\title{
Solutions to Increase PV Hosting Capacity and Provision of Services from Flexible Energy Resources
}

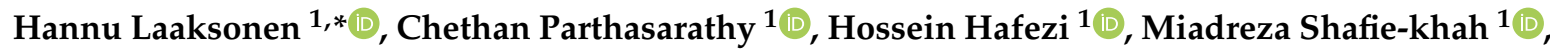 \\ Hosna Khajeh ${ }^{1}$ and Nikos Hatziargyriou ${ }^{2}$ (i) \\ 1 School of Technology and Innovations, Flexible Energy Resources, University of Vaasa, 65100 Vaasa, Finland; \\ chethan.parthasarathy@uwasa.fi (C.P.); hossein.hafezi@uwasa.fi (H.H.); \\ miadreza.shafiekhah@uwasa.fi (M.S.-k.); hosna.khajeh@uwasa.fi (H.K.) \\ 2 School of Electrical and Computer Engineering, National Technical University of Athens, 10682 Athens, \\ Greece; nh@power.ece.ntua.gr \\ * Correspondence: hannu.laaksonen@uwasa.fi
}

Received: 9 June 2020; Accepted: 22 July 2020; Published: 27 July 2020

\begin{abstract}
Future smart grids will be more dynamic with many variabilities related to generation, inertia, and topology changes. Therefore, more flexibility in form of several active and reactive power related technical services from different distributed energy resources (DER) will be needed for local (distribution network) and whole system (transmission network) needs. However, traditional distribution network operation and control principles are limiting the Photovoltaic (PV) hosting capacity of LV networks and the DER capability to provide system-wide technical services in certain situations. New active and adaptive control principles are needed in order to overcome these limitations. This paper studies and proposes solutions for adaptive settings and management schemes to increase PV hosting capacity and improve provision of frequency support related services by flexible energy resources. The studies show that unwanted interactions between different DER units and their control functions can be avoided with the proposed adaptive control methods. Simultaneously, also better distribution network PV hosting capacity and flexibility services provision from DER units even during very low load situations can be achieved.
\end{abstract}

Keywords: distributed energy resources; flexibility services; active network management; frequency control

\section{Introduction}

The potential of active $(P)$ and reactive power $(Q)$ control of distributed energy resources (DER) connected at distribution networks (MV and LV) is expected to be utilized increasingly in the future power systems to manage different renewable energy sources (RES) variabilities related challenges. These challenges related to larger share of RES based generation [1], concern (a) power generation fluctuations and (b) higher variability in power system inertia and fault levels. Moreover, network topologies need to be adapted by active network management (ANM) functionalities including occasionally intended island operation. DER consisting of distributed generation (DG), energy storages (ESs), demand response, or electric vehicles (EVs) can provide flexibility and resiliency for local (distribution system operator, DSO) and system-wide (transmission system operator, TSO) needs. Flexibility can also enable larger scale integration of RES and EVs and minimize the system and societal costs. The effective utilization of flexibilities requires combination and coordination of different types and sizes of resources from all voltage levels (LV, MV, and HV).

Traditionally used fixed on-load-tap-changer's (OLTC's) setting value is rather high because it considers only the existence of customer loads. Additionally, the same OLTC setting value is typically used during the whole year. These traditional OLTC's settings, together with fixed and uncoordinated 
DER units' droop control settings limit the PV hosting capacity of distribution networks and DER ability to provide power system frequency control support during very low load situations. In order to overcome these limitations, more active and adaptive distribution network operation and control principles are needed. Flexibility services provision must be enabled by DER management schemes, regulation, market structures, and business models. DER participation requires new distribution and transmission network operation and planning principles based on active utilization of flexibilities [2].

$P$ and $Q$ related flexibility services by DER can be realized by various inverter local control modes or functions. Inverter control functions such as constant power factor $(\cos \varphi)$, fixed $Q, Q(P), \cos \varphi(P)$, $Q U, P U$, and $P f$, where $f$ is frequency and $U$ is voltage, are already required by different network connection and operation codes. QU-droop control seems to be the preferred and most effective inverter-based DG units' voltage control method in distribution networks [3,4]. In order to increase DG hosting capacity and avoid curtailment of PV active power $P, Q U$-droop is used as a primary voltage control method and $P$ curtailment by $P U$-droop control as a secondary method. In order to achieve the best possible voltage level control in both MV and LV networks simultaneously, the control settings of distribution grid connected DER need to be coordinated with the HV/MV substation's OLTC settings. This improves further DER hosting capacity in distribution networks and reduces network losses [5-7]. Different DER unit control modes, settings, and coordination with OLTC settings should be increasingly considered in the planning stage to obtain the most benefits from the coordinated operation.

Amongst the various DER, battery energy storage systems (BESSs) are expected to play an important role in future smart grids due to their fast and controllable dynamics and potential to provide multiple different flexibility services in stationary applications. In many cases the use of BESS for only one purpose, for example, for (i) improving electricity supply reliability (in case of intended islanding or microgrid operation) or for (ii) increasing distribution network/PV hosting capacity $[8,9]$ may not be an economically viable solution. Therefore, multi-purpose use cases are normally needed for the distribution network connected BESSs. In general, DER control can be roughly divided into local, distributed, and centralized control methods [10-12]. The management scheme can be also a hybrid i.e., combination of centralized and distributed control features. In the literature, different BESS control schemes and sizing principles have been proposed in [13-35]. Different control methods have been also proposed to improve the BESS dynamic inertial response [36]. It can be noted that some of the proposals, such as $[10,36]$, consider only the use of active power $P$ control and do not use the reactive power $Q$ control for local voltage control. It has been shown however that more effective voltage control can be achieved by using both $P$ and $Q$ control capabilities of BESS [8,32]. Due to their rapid response and dynamics, BESSs are also capable of providing system-wide (TSO level) frequency control related services. These services can be realized by an individual large-scale BESS or by aggregating multiple small-scale BESSs $[37,38]$. The optimization of BESS for multi-purpose use in order to provide different local (DSO) and system level (TSO) services should be also taken into account [37].

This paper studies and proposes new solutions and adaptive settings and management schemes in order to increase DER (PV) hosting capacity and the capability of distribution network connected DER to provide flexibility services, predominantly frequency support for system-wide (TSO) needs. In particular, this paper deals with problems such as (1) the coordination between DER units functions and OLTC settings, (2) interactions between different DER units and their control functions, and (3) multi-purpose use of BESS to increase their short- and long-term viability for grid integration (stationary applications). Simulations focus mainly on studying the potential DER (PV and BESS) units QU-, $P U-$, and $P f$-control interactions in different situations. Based on the case studies results, the paper proposes frequency adaptive $P U$-droops and role of $P U$-droops implementation logic with different DER configurations. The way unwanted interactions between DER units and their control functions can be avoided is shown. In addition, novel real-time adaptive management of DER PU-and QU-droops and HV/MV substation transformer's OLTC settings is proposed.

Section 2 of the paper presents the simulated case studies and explains the differences with previous research, the DER droop control settings, and the simulation sequence. Section 3 shows the 
PSCAD simulation results from the main study cases, presents simulation results by utilizing real-life frequency data, and proposes new frequency adaptive PU-droops for PVs and BESSs. In Section 4 new real-time adaptive management schemes for $P U$-droops, $P Q$-flow dependent OLTC settings, and OLTC setting dependent QU-droops are proposed. Finally, conclusions are drawn in Section 5.

\section{Simulation Model and Study Cases}

\subsection{Simulated Study System}

The initial choices made for this paper were based on conclusions from previous research in [39]. Paper [39] studied new multi-objective ANM scheme by simulating local smart grid pilot Sundom Smart Grid (SSG) with different future potential DER scenarios. Currently there are two DG units connected to SSG [39]. One 3.6 MW full-power-converter based wind turbine (WT) connected to MV network with own MV feeder J08 (Figure 1) and another LV network connected inverter based PV unit $(33 \mathrm{~kW})$ at MV/LV substation TR4318 (not included in Figure 1).

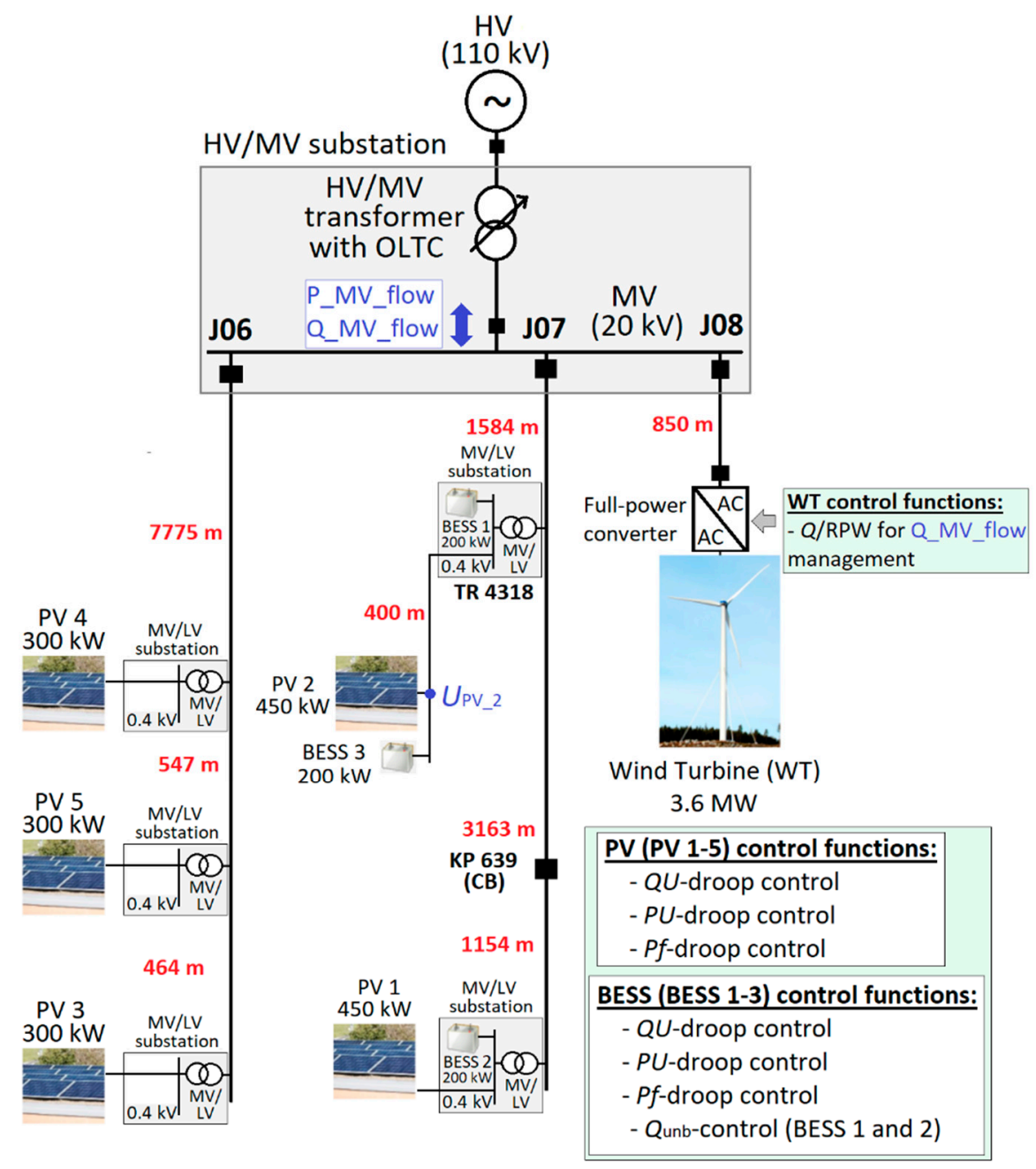

Figure 1. One-line diagram of the studied SSG in future scenario with more PV and BESS units in LV network, as well as with control functions applied in WT, PVs, and BESSs.

However, in the study cases of this paper also future scenarios with higher amount of PV units as well as with BESSs connected in LV network of SSG (Figure 1) are evaluated. As shown in Figure 1, in the studied future scenario there are two $450 \mathrm{~kW}$ PV units (PV 1 and PV 2) at MV feeder J07 and three $300 \mathrm{~kW}$ PV units (PV 3-5) at MV feeder J06. Respectively, three $200 \mathrm{~kW}$ BESS units (BESSs 1-3) 
were added to MV feeder J07 in different locations (Figure 1). Figure 1 also shows what type of control functions are applied in the studies of this paper for WT, PVs, and BESSs. Differences to the previous studies in [39] can be also seen in Table 1.

Table 1. Main focus areas of previous studies [39] and research work done in this paper.

\begin{tabular}{l}
\hline Previous Studies [39] \\
\hline - Type of DER units \\
- $\quad$ PV units (300 kW) and WT (3.6 MW) \\
Average models with controlled voltage sources \\
2. Droops and control functions of DER units \\
- $\quad$ Utilization of WT or PVs to fulfill RPW-limits \\
- $\quad$ Different $Q U$ - - (seasond $P U$-droop also on $W T$ \\
- One Pf-droop for PVs
\end{tabular}

0. Initial choices (based on [39] findings)

- $\quad$ No QU- and PU-droops on WT

- Only Fingrid RPW-limits used which are fulfilled by the control of WT reactive power

\section{Type of DER units}

- $\quad$ PV units (300 and $450 \mathrm{~kW})$, BESS units (200 kW) and WT (3.6 MW), see Figure 1 and Table 2

- Average models with controlled voltage sources

2. Droops and control functions of DER units

- $\quad$ See Figure 1

\section{Focus on}

\section{Focus on}

- Multi-objective ANM scheme

- $\quad$ Different RPW-limits (Fingrid and ENTSO-E) and control of reactive power flow between $\mathrm{HV}$ and MV networks

- $\quad$ Effect of different OLTC setting values (20.7 or $20.0 \mathrm{kV}$ )

- Mutual/conflicting requirements between WT control functions) (QU-droop 2 and $Q$-control to fulfill RPW-limits)

- Very low and high load situations

- Solutions to increase PV hosting capacity in LV network as well as provision of services from LV network connected DER

- Coordination between DER unit functions and OLTC settings

- $\quad$ Multi-purpose use of BESS

- $\quad$ Potential DER (PV and BESS) unit Pf- and $P U$-control interactions in different situations

- $\quad$ New frequency adaptive PU-droops (Section 3.2)

- $\quad$ Role of PU-droops implementation logic with different DER configurations

$\bigcirc \quad$ For example, effect of $P U$-blocking with PVs (only) and with PVs + BESSs

- $\quad$ Very low load situations

4. In addition, this paper presents new real-time adaptive management schemes (Section 4) for

DER units' PU-droops,

HV/MV substation transformer's OLTC setting value and DER units' QU-droops

In this paper, the studies were undertaken by utilizing Fingrid's (Finnish TSO) Reactive Power Window (RPW)-limits (see [39]) in scenarios with more PVs and BESSs (Figure 1) than in [39]. In the studied cases, WT alone is responsible for fulfilling the Fingrid's RPW-limits (Figure 1). In addition, during normal operation WT close to HV/MV substation does not need to have QU- or PU-droops. This also prevents potential mutual effects between control functions, which were reported in [39]. However, if WT would be connected to network in some back-up feeding configuration (e.g., during Sundom HV/MV primary transformer maintenance), then suitable $Q U$ - and $P U$-droops could be used. The main focus areas of previous studies in [39] and research work in this paper are summarized in Table 1. 


\subsection{Droop Control of the DER Units}

Figure 1 in Section 1 presented the type of control functions applied in the studies for WT, PVs, and BESSs. Voltage control of MV and LV distribution network is managed by HV/MV substation OLTC setting as well as by QU- and PU-droop control of PV and BESS units. In the simulations $Q U$-droop control of the DER units is used as the primary local voltage control method and PU-droop control as the secondary method in order to avoid unnecessary $P$ curtailment of PV units.

Increased reactive power $Q$ production (Equation (1)) of cables during very high voltages and very low load currents can potentially lead to local overvoltage situations in the distribution network and therefore seasonal OLTC setting values could be used to improve DER hosting capacity of the network.

$$
Q_{\text {cable }}=Q_{\text {production }}-Q_{\text {consumption }}=\omega C U^{2}-3 \omega L I^{2},
$$

where

$\omega=$ angular frequency,

$C=$ cable capacitance,

$U=$ cable voltage,

$L=$ inductance/phase,

$I=$ cable current.

In order to improve distribution network PV hosting capacity, the OLTC setting during very high load (winter season, total load $6548 \mathrm{~kW}, 283 \mathrm{kVAr}$ ) was chosen to be $20.3 \mathrm{kV}(1.015 \mathrm{pu})$. Reactive power $Q$ produced by cables is dependent on voltage (Equation (1)) and therefore lower OLTC setting is more suitable during summer time when cable load current $I$ dependent reactive power consumption is also smaller. In the simulations during very-low load (summer season, total load $970 \mathrm{~kW},-660 \mathrm{kVAr}$ ) the set value of OLTC was $20.0 \mathrm{kV}(1.0 \mathrm{pu})$ with dead-zone $\pm 0.3 \mathrm{kV} / 0.015 \mathrm{pu}$ and $7.0 \mathrm{~s}$ operation time delay (due to short simulation time $t=110 \mathrm{~s}$ ). Total load includes also $P$ losses and $Q$ produced/consumed by cables and overhead lines.

Respectively, seasonal QU- and PU-droops should be utilized for DER units in order to improve the DER hosting capacity of the distribution network. In addition, the seasonal $Q U$ - and $P U$-droops should be compatible with the seasonal OLTC setting values as well as coordinated between different type of units. This means that, for example, PU-droop settings of PV and BESS units at the same connection point should be coordinated so that unnecessary active power curtailment of PV unit due to local overvoltage can be avoided by simultaneous charging of the BESS unit.

The used QU-droops, $P U$-droops, and Pf-droop of PV and BESS units are shown in Figure 2. It can be noted that BESSs 1 and 2 (Figure 1) have also the $Q_{\text {unb-control responsibility in order to enable }}$ correct operation of passive islanding detection methods [40-42]. In many grid codes, like in ENTSO-E NC RfG [43], the required reactive power feeding/absorbing capability of the DER units is defined to be range $\cos (\varphi)=0.95_{\text {ind/cap }}$ and that has been also used in this paper for defining the reactive power limits of the DER unit (PV and BESS) QU-droops (Figure 2a,b). The basis for dimensioning the DC/AC converter of the PV unit can be found e.g., from [44]. However, in order to reduce the needed simulation time with multiple connected DER units (PVs, BESSs, and WT), average models with controlled voltage sources are used instead of actual power-electronics switches in PSCAD models utilized in the studies of this paper.

In the simulation studies of this paper, PV and BESS units had different chosen $Q U$-droops for winter (PV/BESS QU-droop 2, Figure 2a,b) and summer time (PV/BESS QU-droop 1, Figure 2a,b). Dead-zone of $Q U$-droops during summer time was chosen to be smaller in order to compensate more reactive power produced by cables during very low load. In the studies, coordinated PU-droop settings of PV and BESS units were also used (Figure 2c).

In addition, $P V$ and BESS units have $P f$-droop functions (Figures 1 and $2 \mathrm{~d}$ ) in order to participate in frequency control during over-/under-frequency situations. In the simulations, two different $P f$-droops 
for PVs and BESSs with smaller and larger dead-zones were utilized (Figure 2d). The $P f$-droops smaller dead-zones are used during summer time (PV/BESS $P f$-droop 1, Figure 2d) when there is typically also less inertia in the power system and need for more rapid response from DER units to support the power system frequency. The used $P f$-droops are also more sensitive than those required by the grid codes, because the idea is that the PV and BESS units could offer participation in frequency control as a flexibility service, for example, through a flexibility marketplace.

The implementation of PV unit's active and reactive power droop control functions in the used PSCAD model is shown in Figure 3 (see also Figures 1 and 2). From Figure 3 it can be seen how the active and reactive power controllers with respective droop functions ( $Q U-, P U-$, and $P f$-droops) will create the active and reactive power references (P_ref, $\left.Q_{-} r e f\right)$ which are further processed in order to have current reference values $\left(I_{\mathrm{d}_{-} \text {ref }}, I_{\mathrm{q}_{-} \text {ref }}\right)$ for the current controller. The current controller (Figure 3 ) then gives the voltage reference values $\left(V_{-} r e f\right)$ for the controlled voltage sources in the PSCAD model. In the simulations it was also found out that the mutual effects of $P f$ - and $P U$-control functions on PV 2 (Figure 1) during over-frequency support participation need additional blocking logic (PU-blocking in Figure 3) in the control system. Otherwise, the active power of PV unit PV 2 needs to be curtailed and it cannot participate in frequency control due to mutual interaction of $P f$ - and $P U$-control functionalities. In the PSCAD simulations, the control functionality of BESS units was very similar when compared to the PVs (Figure 3).

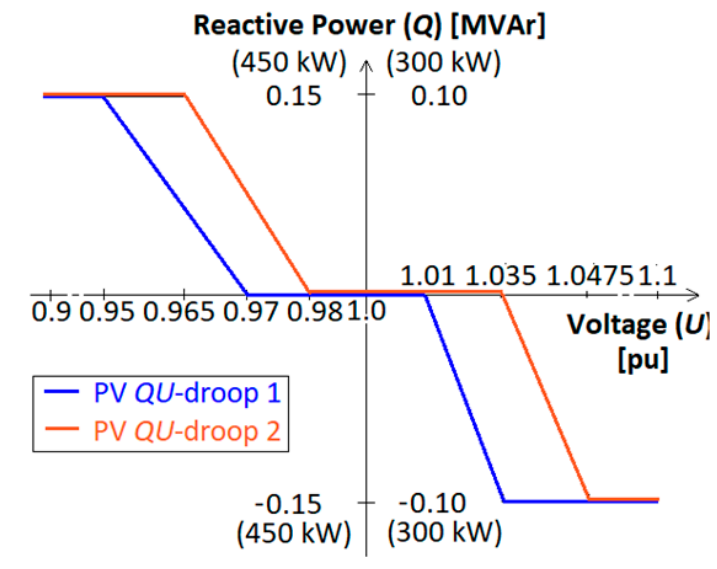

a)

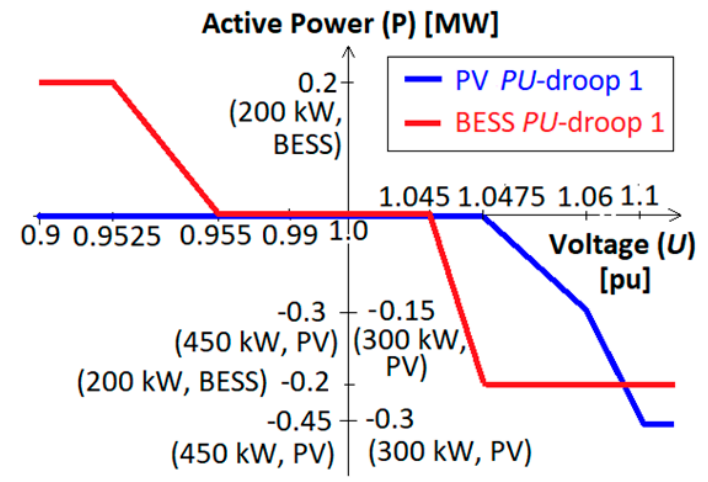

c)

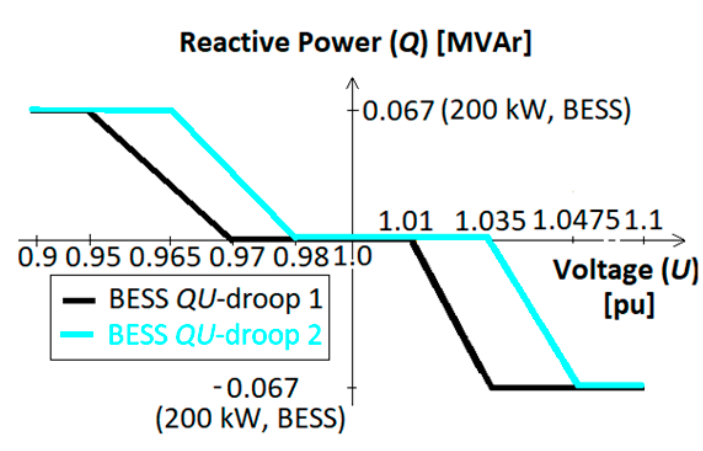

b)

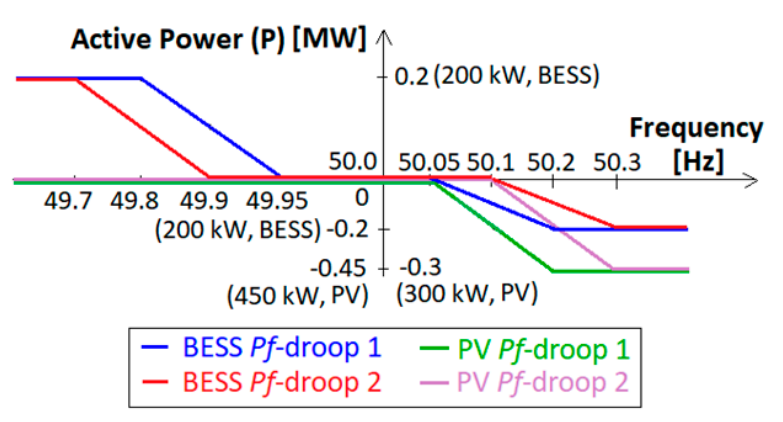

d)

Figure 2. (a) QU-droop settings of PV units, (b) QU-droop settings of BESS units, (c) PU-droop settings of PV and BESS units, and (d) Pf-droop settings of BESS units which were used in the PSCAD simulations (see also Figures 1 and 3 ). 


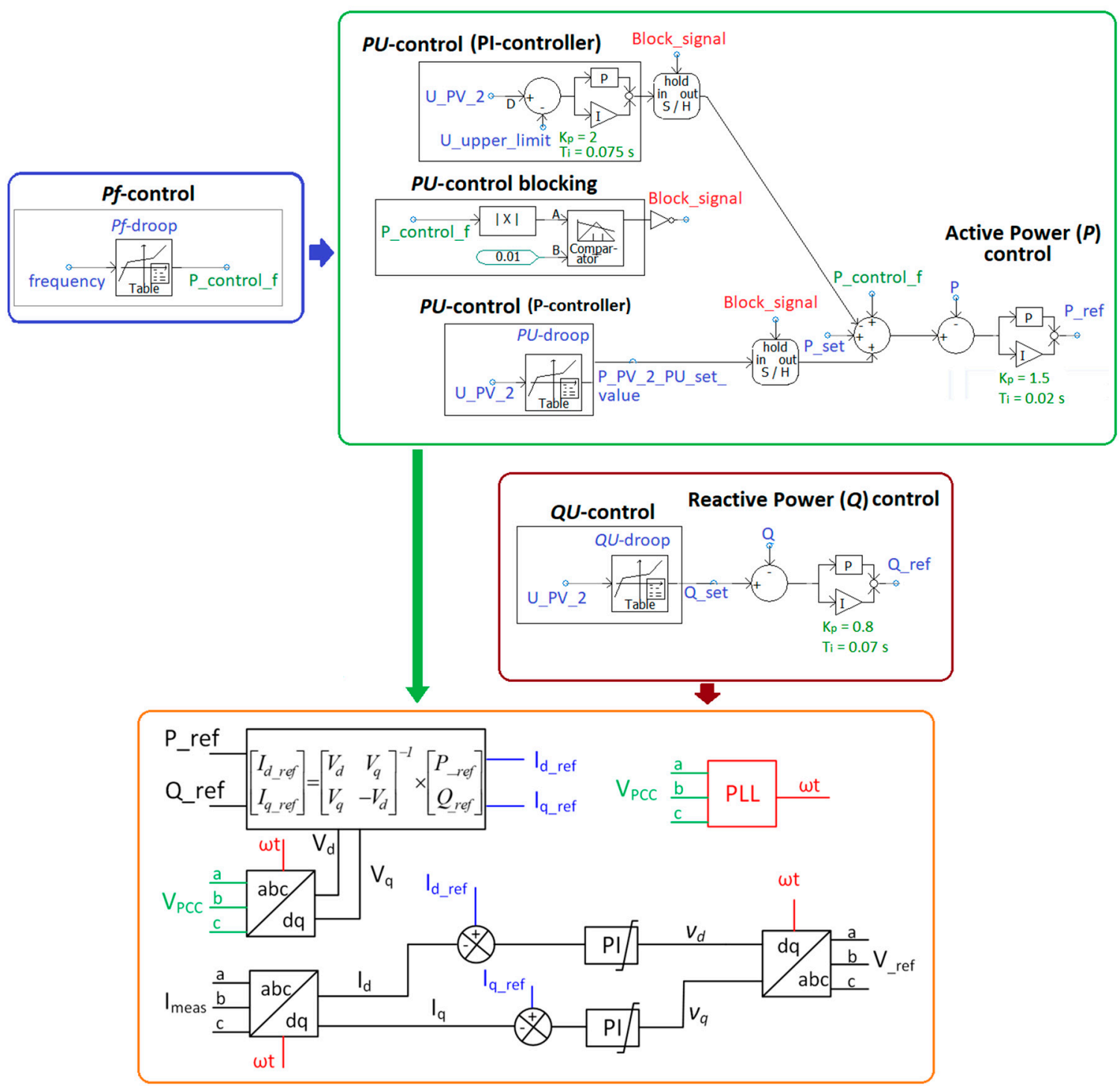

Figure 3. PV unit's active and reactive power control functions like $Q U-, P U-$, and $P f$-droops implementation in PSCAD model (see also Figures 1 and 2).

\subsection{Study Cases and Simulation Sequence}

Table 2 shows the study cases presented in this paper and used $Q U-, P U-$, and $P f$-droops for the PV and BESS units (Figure 2). In all cases (Table 2), over- and under-voltage limits were 1.05 and $0.95 \mathrm{pu}$ and OLTC dead-zone was $\pm 0.3 \mathrm{kV} / 0.015 \mathrm{pu}$. In order to highlight the effect of adapting the OLTC setting during very low load situations, simulations with OLTC setting value $20.7 \mathrm{kV}$ (1.035 pu) were also included in the simulation results (Table 2). Voltage limits of 0.95 and 1.05 pu were chosen as steady-state operation target limits in order to guarantee stable voltage level and high power quality in LV network. In addition, all simulation cases presented in the following were simulated with only P-controllers on PVs and BESSs for PU-control (see Table 2 and Figure 3). In Table 3, the used simulation sequence and other issues regarding study cases (Table 2) are presented. 
Table 2. Simulation study cases, very low load in all cases (see Figure 2).

\begin{tabular}{|c|c|c|c|c|c|c|c|c|}
\hline Case & WTs $* *)$ & PVs ${ }^{* *)}$ & BESSs $* *)$ & $\begin{array}{l}\text { QU-Droop of } \\
\text { PVs/BESSs }\end{array}$ & $\begin{array}{l}\text { PU-Droop of } \\
\text { PVs/BESSs }\end{array}$ & $\begin{array}{l}P f \text {-Droop of } \\
\text { PVs/BESSs }\end{array}$ & $\begin{array}{c}\text { PU-Blocking } \\
\text { with PVs/BESSs }\end{array}$ & $\begin{array}{l}\text { OLTC Set } \\
\text { Value } \\
(\mathrm{kV}) /(\mathrm{pu})\end{array}$ \\
\hline $1 \mathrm{a}$ & 1 & 5 & 0 & $1 /-$ & $1 /-$ & $1 /-$ & No & $20.7 / 1.035$ \\
\hline $2 a$ & 1 & 5 & 0 & $1 /-$ & $1 /-$ & $1 /-$ & Yes & $20.7 / 1.035$ \\
\hline $2 b$ & 1 & 5 & 0 & $1 /-$ & $1 /-$ & $1 /-$ & Yes & $20.0 / 1.0$ \\
\hline $3 a$ & 1 & 5 & 0 & $2 /-$ & $1 /-$ & $2 /-$ & Yes & $20.7 / 1.035$ \\
\hline $4 b^{*)}$ & 1 & 5 & 2 & $1 / 1$ & $1 / 1$ & $1 / 1$ & Yes & $20.0 / 1.0$ \\
\hline $5 a$ & 1 & 5 & 3 & $1 / 1$ & $1 / 1$ & $1 / 1$ & No & $20.0 / 1.0$ \\
\hline $5 b$ & 1 & 5 & 3 & $1 / 1$ & $1 / 1$ & $1 / 1$ & Yes & $20.0 / 1.0$ \\
\hline
\end{tabular}

WT is wind turbine, PV is photovoltaic unit, BESS is battery energy storage unit, *) remote voltage (U_PV_2) measurement from PV 2 connection point to BESS 1 control through communication, ${ }^{* *}$ ) number of units.

Table 3. Simulation sequence actions and other issues in study cases (see Table 2 and Figure 1). Total simulation time $t=110 \mathrm{~s}$

\begin{tabular}{cc}
\hline Time (s) & Initial Condition/Action \\
\hline$t=0-110$ & PV unit active power $\left(P_{\mathrm{PV}}\right)$ is at nominal ${ }^{*)}$ i.e., 300 or $450 \mathrm{~kW}$ \\
$t=10.5$ & WT active power $\left(P_{\mathrm{WT}}\right)$ increases from initial 0.5 to $\left.1.5 \mathrm{MW} *\right)$ \\
$t=15.0$ & WT active power $\left(P_{\mathrm{WT}}\right)$ increases from 1.5 to $\left.2.5 \mathrm{MW} *\right)$ \\
$t=19.0$ & WT active power $\left(P_{\mathrm{WT}}\right)$ increases from 2.5 to $\left.3.6 \mathrm{MW} *\right)$ \\
$t=30-40$ & Over-frequency situation $\left.(50.07 \mathrm{~Hz})^{* *}\right)$ \\
$t=50-60$ & Over-frequency situation $(50.25 \mathrm{~Hz})^{* *}$ \\
$t=70-80$ & Under-frequency situation $(49.9 \text { or } 49.4 \mathrm{~Hz})^{* *)}$ \\
$t=90-100$ & Under-frequency situation $\left.(49.8 \text { or } 49.4 \mathrm{~Hz})^{* *}\right)$ \\
Other issues & Part of the load participates in demand response and disconnects from the LV network \\
& In all study cases of Table 2 PVs $Q U$-droop is primary and $P U$-droop secondary local \\
\hline
\end{tabular}

*) If voltage at PV or WT connection point is between min. and max. limits, **) Pf-control of PVs/BESSs participates in frequency control according to their $P f$-droops.

\section{Simulation Results and New Frequency Adaptive $P U$-Droop}

In this section, the main simulation results regarding potential solutions which could increase LV distribution networks' PV hosting capacity and provision of flexibility services from small-scale DER are presented. In Section 3.1, the focus of the simulations was in the following issues (Table 2):

- $\quad$ Effect of BESSs utilization (Cases 4a-5b), two or three BESSs (with default PU-droops on BESSs).

- Potential DER (PV and BESS) unit $P f$ - and PU-control interactions during future scenarios with very high PV penetration and very low load in (i) steady-state, (ii) over-frequency, and (iii) under-frequency situations to study the effect of:

additional $P U$-control blocking logic (Cases $2 \mathrm{a}-4 \mathrm{~b}$ and $5 \mathrm{~b}$ );

$\bigcirc \quad$ different $P f$ - and QU-droop settings (Cases 3a-3b).

- Effect of remote LV voltage measurement from PV (further in LV network) connection point to BESS at closest MV/LV secondary substation in order to maximize PV production during very low loads (Case $4 b$ ).

- Effect of adapting the OLTC setting during very low load situations (Cases 1b, 2b, 3b, and 4a-5b).

After that, Section 3.1 presents simulation results by utilizing measured $30 \mathrm{~min}$ real-life frequency data from SSG (Case 6). Finally, in Section 3.2. frequency adaptive PU-droops for PVs and BESSs during larger under- and over-frequency situations are proposed (Cases $7 \mathrm{a}-7 \mathrm{~b}$ ). 
3.1. Simulations to Study Different Potential Solutions for Increasing LV Network PV Hosting Capacity and Provision of Flexibility Services from DER

In the following, simulation results from different very low load cases (Tables 2 and 3) with only P-controllers for PU-control in PVs and BESSs (Figure 3) are explained in detail. At first, Table 4 presents PV 2 unit's (Figure 1$)$ active $\left(P_{\mathrm{PV}_{-} 2}\right)$ and reactive $\left(Q_{\mathrm{PV} \_}\right)$power as well as PV 2 connection point voltage $\left(U_{\mathrm{PV}_{-} 2}\right)$ during over- and under-frequency events in different cases. After that, Tables 5 and 6 show the active and reactive power of BESS 1 and 3 during over- and under-frequency events in different cases. In order to highlight the PV hosting capacity in PV 2 connection point, Figure 4 presents the active power $\left(P_{\mathrm{PV}_{-} 2}\right)$ values of PV 2 during steady-state, over- and under-frequency events in different cases.

From Table 4 and Figure 4 it can be seen that the PV hosting capacity in PV 2 connection point (Figure 1) without BESSs in Cases 1a-3b during steady-state operation $(t=25.0 \mathrm{~s})$ can be increased with lower $(20.0 \mathrm{kV}$ ) OLTC setting (Cases $1 \mathrm{~b}, 2 \mathrm{~b}, 3 \mathrm{~b}$ ). During over-frequency event $50.07 \mathrm{~Hz}(t=25.0 \mathrm{~s}$ ) in Cases 1a-3b without BESSs one can see that best frequency support (frequency control participation) can be achieved in Cases $2 \mathrm{a}$ and $2 \mathrm{~b}$ with utilization of $P U$-control blocking logic (Figure 3 ) and $P f$-droop 1 (Figure 2) on PVs. On the other hand, during under-frequency event $49.8 \mathrm{~Hz}(t=95.0 \mathrm{~s}$ ) in Cases $1 \mathrm{a}-3 \mathrm{~b}$ without BESSs it can be seen from Table 4 and Figure $4 \mathrm{c}$ that due to load demand response participation to frequency support by disconnecting part of the load at PV 2 connection point, also the PV 2 active power needs to be curtailed in order to avoid local over-voltages. However, this PV curtailment during under-frequency event is not feasible from system-wide perspective and reduces the effect of load demand response to frequency control. Table 4 results also show that, due to used P-controllers for PU-control in PV 2 and BESS 3 without any PI-controllers (Figure 3), small voltage limit violations at the PV 2 connection point voltage $\left(U_{\mathrm{PV}_{-} 2}\right)$ can be possible.

Table 4. PV 2 active $\left(P_{\mathrm{PV} \_2}\right)$ and reactive $\left(Q_{\mathrm{PV} \_2}\right)$ power as well as PV 2 connection point voltage $\left(U_{\mathrm{PV} \_}\right)$during over- and under-frequency events in different cases (Figures 1 and 2, Tables 2 and 3).

\begin{tabular}{|c|c|c|c|c|c|}
\hline Case & $\begin{array}{c}\text { Load } \\
\text { Level }\end{array}$ & $\begin{array}{c}P_{P V \_2}, Q_{P V \_2}, U_{P V \_2} \\
\text { Steady-State, } t=25 \mathrm{~s} \\
(\mathrm{~kW}, \mathrm{kVAr}, \mathrm{pu})\end{array}$ & $\begin{array}{c}P_{\mathrm{PV} \_2}, Q_{\mathrm{PV} \_2}, U_{\mathrm{PV} \_2} \\
50.07 \mathrm{~Hz}, t=35 \mathrm{~s} \\
(\mathrm{~kW}, \mathrm{kVAr}, \mathrm{pu})\end{array}$ & $\begin{array}{c}P_{\mathrm{PV} \_2}, Q_{\mathrm{PV} \_2}, U_{\mathrm{PV} \_2} \\
50.25 \mathrm{~Hz}, t=55 \mathrm{~s} \\
(\mathrm{~kW}, \mathrm{kVAr}, \mathrm{pu})\end{array}$ & $\begin{array}{c}P_{\mathrm{PV} 22}, Q_{\mathrm{PV} \_2}, U_{\mathrm{PV} 22} \\
\left.49.8 \mathrm{~Hz}, t=95 \mathrm{~s}^{*}\right) \\
(\mathrm{kW}, \mathrm{kVAr}, \mathrm{pu})\end{array}$ \\
\hline $1 \mathrm{a}$ & Low & $243,-150,1.056$ & $236,-150,1.054$ & $0,0,1.006$ & $213,-150,1.057$ \\
\hline $1 b$ & Low & $316,-150,1.053$ & $310,-150,1.051$ & $0,0,0.976$ & $286,-150,1.054$ \\
\hline $2 \mathrm{a}$ & Low & $243,-150,1.056$ & $190,-150,1.038$ & $0,0,1.006$ & $213,-150,1.057$ \\
\hline $2 b$ & Low & $316,-150,1.053$ & $264,-150,1.035$ & $0,0,0.976$ & $286,-150,1.054$ \\
\hline $3 a$ & Low & $241,-150,1.056$ & $242,-150,1.056$ & $0,0,1.006$ & $210,-150,1.057$ \\
\hline $3 b$ & Low & $316,-150,1.053$ & $317,-150,1.053$ & $0,10,0.979$ & $286,-150,1.054$ \\
\hline $4 a$ & Low & $316,-150,1.053$ & $264,-150,1.035$ & $0,0,0.974$ & $281,-150,1.055$ \\
\hline $4 b$ & Low & $334,-150,1.052$ & $282,-149,1.035$ & $0,0,0.974$ & $298,-150,1.054$ \\
\hline $5 a$ & Low & $450,-150,1.046$ & $390,-150,1.039$ & $0,140,0.950$ & $363,-150,1.051$ \\
\hline $5 b$ & Low & $450,-150,1.046$ & $390,-139,1.033$ & $0,150,0.935$ & $245,-150,1.056$ \\
\hline
\end{tabular}

*) Part of the load also at PV_2 connection point participates in demand response and disconnects from the LV network.

Table 5. BESS 1 active $\left(P_{\text {BESS_1 }}\right)$ and reactive $\left(Q_{\text {BESS_1 }}\right)$ power during over- and under-frequency events in different cases (Figures 1 and 2, Tables 2 and 3).

\begin{tabular}{|c|c|c|c|c|c|}
\hline Case & $\begin{array}{c}\text { Load } \\
\text { Level }\end{array}$ & $\begin{array}{c}P_{\text {BESS_1 }}, Q_{\text {BESS_1 }} \\
\text { Steady-State, } t=25 \mathrm{~s} \\
(\mathbf{k W}, \mathrm{kVAr})\end{array}$ & $\begin{array}{l}P_{\text {BESS_1 }}, Q_{\text {BESS_1 }} \\
50.07 \mathrm{~Hz}, t=35 \mathrm{~s} \\
(\mathrm{~kW}, \mathrm{kVAr})\end{array}$ & $\begin{array}{c}P_{\text {BESS_1 }}, Q_{\text {BESS } 11} \\
50.25 \mathrm{~Hz}, t=55 \mathrm{~s} \\
(\mathrm{~kW}, \mathrm{kVAr})\end{array}$ & $\begin{array}{c}P_{\text {BESS_1 }}, Q_{\text {BESS_1 }} \\
49.8 \mathrm{~Hz}, t=95 \mathrm{~s} \\
(\mathrm{~kW}, \mathrm{kVAr})\end{array}$ \\
\hline $4 a$ & Low & 0,0 & $-27,0$ & $-200,0$ & 200,0 \\
\hline $4 b$ & Low & $-200,-67$ & $-200,0$ & $-200,-67$ & $0,-67$ \\
\hline $5 a$ & Low & 0,0 & $-27,0$ & $-200,0$ & 200,0 \\
\hline $5 b$ & Low & 0,0 & $-27,0$ & $-200,0$ & 200,0 \\
\hline
\end{tabular}


Table 6. BESS 3 active $\left(P_{\text {BESS_3 }}\right)$ and reactive $\left(Q_{\text {BESS_3 }}\right)$ power during over- and under-frequency events in different cases (Figures 1 and 2, Tables 2 and 3).

\begin{tabular}{|c|c|c|c|c|c|}
\hline Case & $\begin{array}{l}\text { Load } \\
\text { Level }\end{array}$ & $\begin{array}{c}P_{\text {BESS_3, }} Q_{\text {BESS_3 }} \\
\text { Steady-State, } t=25 \mathrm{~s} \\
(\mathrm{~kW}, \mathrm{kVAr})\end{array}$ & $\begin{array}{c}P_{\text {BESS_3 }}, Q_{\text {BESS_3 }} \\
50.07 \mathrm{~Hz}, t=35 \mathrm{~s} \\
(\mathrm{~kW}, \mathrm{kVAr})\end{array}$ & $\begin{array}{c}P_{\text {BESS_3 }}, Q_{\text {BESS_3 }} \\
50.25 \mathrm{~Hz}, t=55 \mathrm{~s} \\
(\mathrm{~kW}, \mathrm{kVAr})\end{array}$ & $\begin{array}{c}P_{\text {BESS_3 }}, Q_{\text {BESS_3 }} \\
49.8 \mathrm{~Hz}, t=95 \mathrm{~s} \\
(\mathrm{~kW}, \mathrm{kVAr})\end{array}$ \\
\hline $5 a$ & Low & $-93,-67$ & $-52,-67$ & $-165,62$ & $-25,-67$ \\
\hline $5 b$ & Low & $-93,-67$ & $-84,-62$ & $-200,67$ & $108,-67$ \\
\hline
\end{tabular}

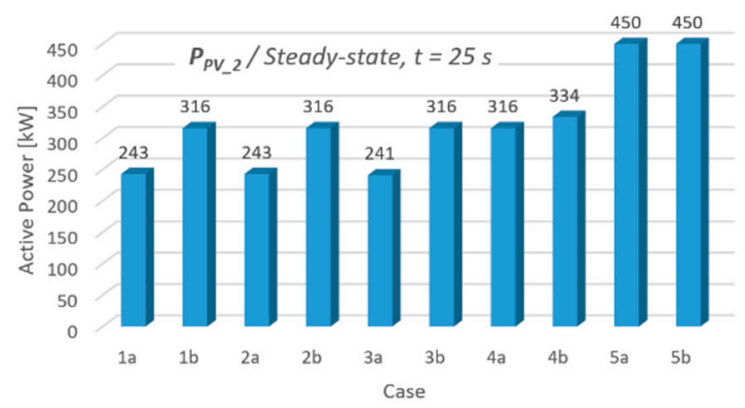

a)

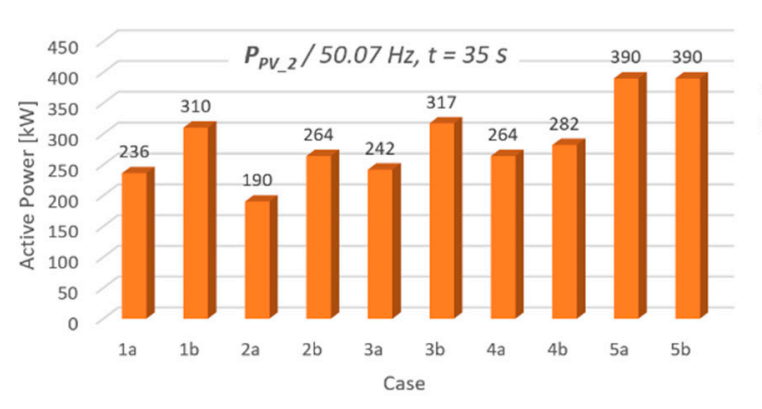

b)

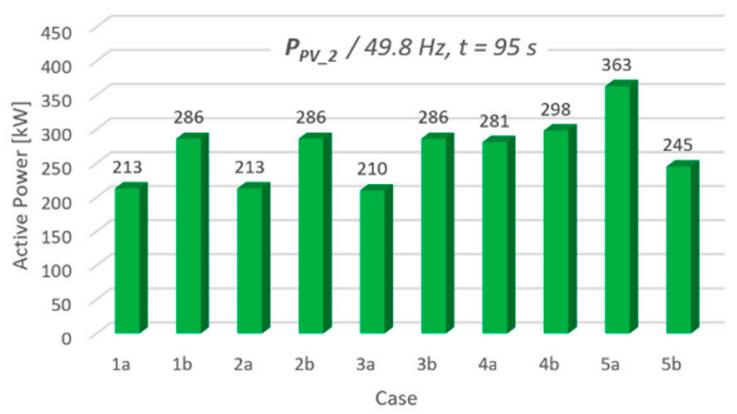

c)

Figure 4. PV 2 's active power $\left(P_{\mathrm{PV} \_2}\right)$ values in different cases with very low load during $(\mathbf{a})$ steady-state,

(b) over- and (c) under-frequency events (see also (Figures 1 and 2, Tables 2-6)).

The effect of BESS 1 and 3 (Figure 1) on the PV hosting capacity in PV 2 connection point can be seen from Cases $4 a-5 b$ (Tables 4-6, Figure 4). When comparing Cases $4 a$ and $4 b$ with BESS 1 during steady-state operation ( $t=25.0 \mathrm{~s}$ ) one can see that PV 2 hosting capacity can be only be increased in Case $4 \mathrm{~b}$ in which remote LV voltage measurement from PV 2 connection point to BESS 1 (Figure 1) control is utilized through communication. In Cases $5 a$ and $5 b$ with BESS 3 at the PV 2 connection point however, the PV hosting capacity during steady-state operation $(t=25.0 \mathrm{~s}$, Figure $4 \mathrm{a})$ can be maximized by simultaneously charging BESS 3 (Table 6) in order to avoid local over-voltages. By comparing the simulation results of Cases $5 \mathrm{a}$ and $5 \mathrm{~b}$ (Tables 4-6) during over-frequency event $50.25 \mathrm{~Hz}(t=55.0 \mathrm{~s})$ the effect of PU-control blocking logic of PVs and BESSs can be seen. The PU-blocking maximizes the BESS 3 participation in frequency support in Case $5 \mathrm{~b}$ (Table 6), but simultaneously leads to local under-voltage at PV 2 connection point (Table 4). During under-frequency event $49.8 \mathrm{~Hz}(t=95.0 \mathrm{~s})$ in Cases $5 \mathrm{a}$ and $5 \mathrm{~b}$ with BESS 3 it can be seen from Tables 4 and 6 that in Case $5 \mathrm{a}$ without $P U$-blocking total active power change (PV2 + BESS 3) is $\Delta P_{5 \mathrm{a}_{2} 49.8 \mathrm{~Hz}}=\Delta P_{\mathrm{PV} 2}(-87 \mathrm{~kW})+\Delta P_{\mathrm{BESS}} 3(68 \mathrm{~kW})=-19 \mathrm{~kW}$ and in Case 5b with $P U$-blocking $\Delta P_{5 \mathrm{~b} \_49.8 \mathrm{~Hz}}=\Delta P_{\mathrm{PV} 2}(-205 \mathrm{~kW})+\Delta P_{\mathrm{BESS} 3}(201 \mathrm{~kW})=-4 \mathrm{~kW}$. The total active power change is quite similar in Cases $5 a$ and $5 b$, but it seems that in cases with PV and BESS at the same connection point, the $P U$-blocking (Case 5b) may lead to unnecessary large PV curtailment during under-frequency events if BESS unit participates in frequency control. This issue is further studied in Section 3.2. 
Simulations with Real-Life Measurement Data

In this Section, the aim was to study PV 2 and BESS 3 unit's (Figure 1$)$ active $\left(P_{\text {PV_2 }}\right)$ and reactive $\left(Q_{P V}{ }_{2}\right)$ power as well as PV 2 connection point voltage $\left(U_{P V \_2}\right)$ in Case 5 by utilizing measured real-life frequency data from SSG (Figure 5). Measured $30 \mathrm{~min}$ frequency data (Figure 5) was modified for PSCAD simulations to $240 \mathrm{~s}$ input data and was utilized in the new simulation Case 6 during $t=$ 10-250 s (Figure 6a).

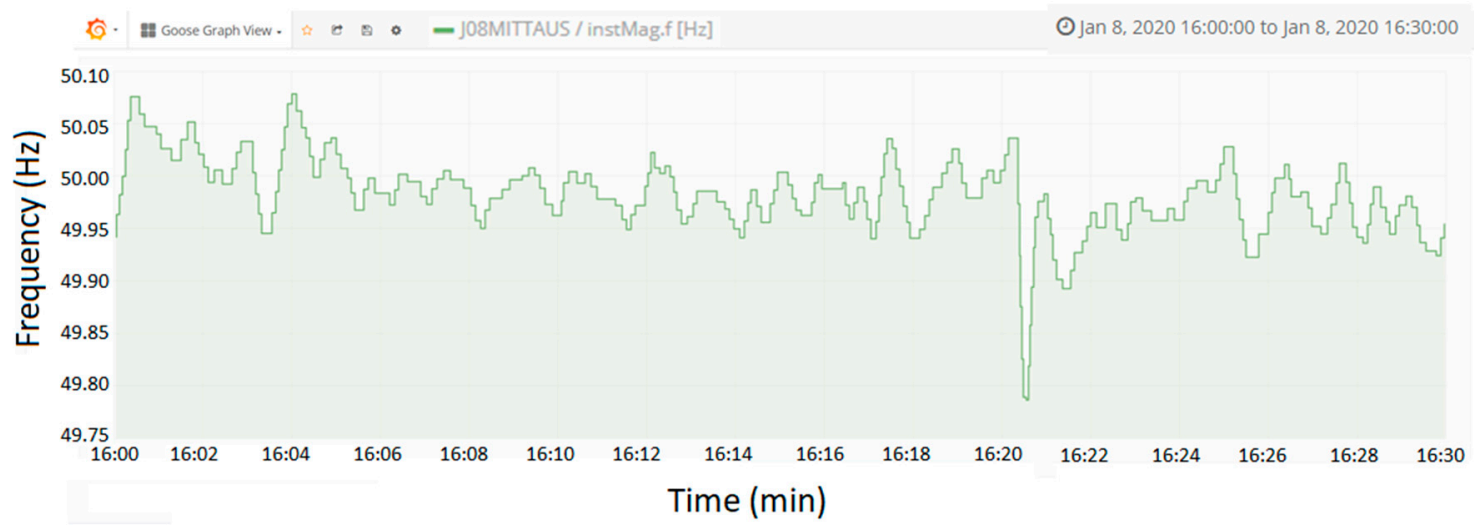

Figure 5. Measured 30 min real-life frequency data from SSG (which is modified for PSCAD simulations to $240 \mathrm{~s}$ frequency input data between $t=10-250 \mathrm{~s}$, see Figure $6 \mathrm{a})$.

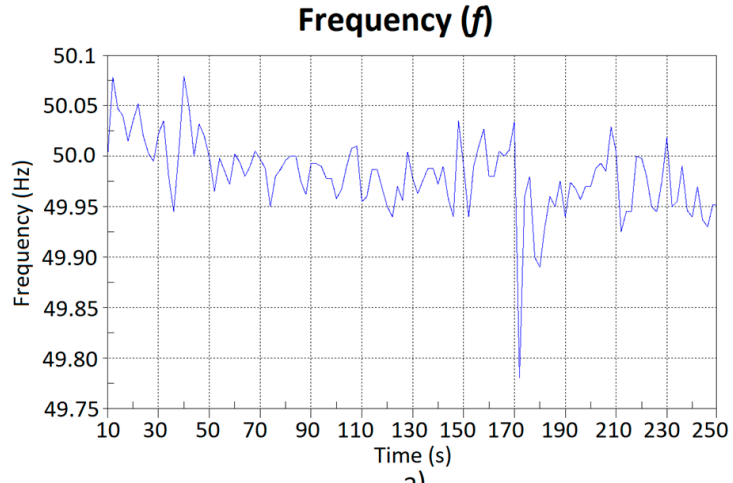

a)

Active Power $(P)$

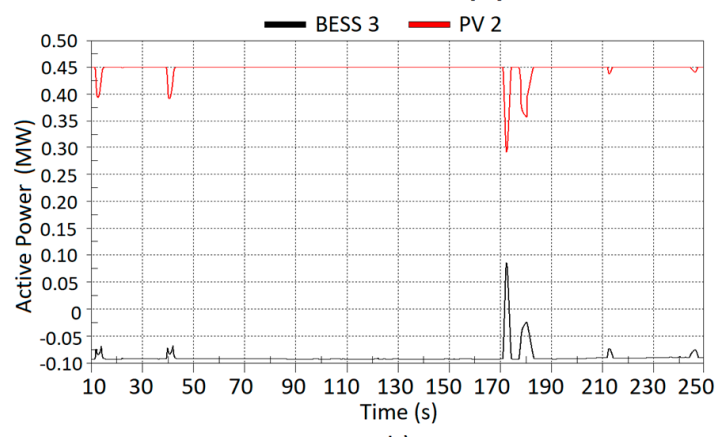

b)

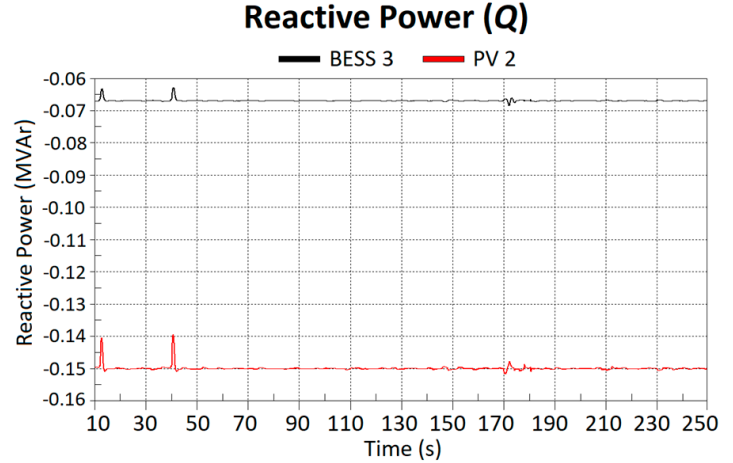

c)

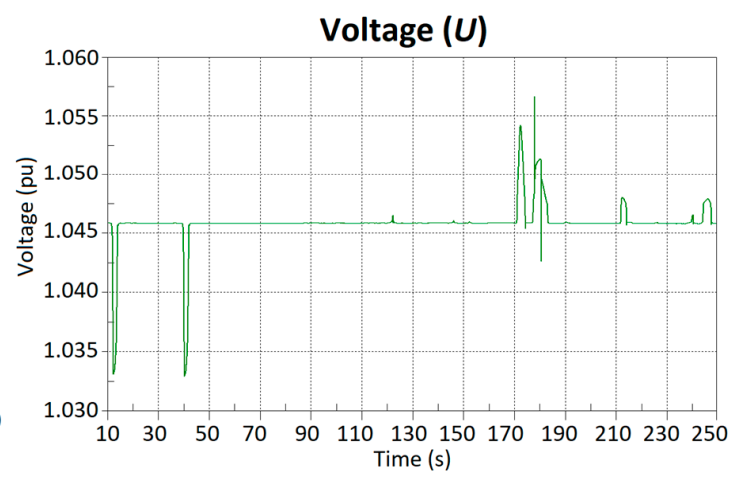

d)

Figure 6. (a) Input frequency $(f)$ data modified from real-life SSG measurements (Figure 5), PV 2 and BESS $3(\mathbf{b})$ active $(P)$ and $(\mathbf{c})$ reactive power $(Q)$, as well as $(\mathbf{d})$ local voltage $(U)$ behavior at PV 2 connection point during simulated Case 6 (similar to Case 5, see also Figures 1 and 2, Tables 2-6).

From simulation results of Figure 6 it can be seen how PV 2 and BESS 3 units participate in frequency control when frequency exceeds $50.05 \mathrm{~Hz}$. In a similar manner, BESS 3 participates in frequency 
control during under-frequencies (i.e., when frequency is smaller than $49.95 \mathrm{~Hz}$ ). In addition, during $t=178.0-180.5 \mathrm{~s}$ also load demand response participates in frequency support by load disconnection when under-frequency limit $49.90 \mathrm{~Hz}$ is exceeded. Due to local voltage rise at PV 2 connection point during under-frequency events also PV 2 active power needs to be simultaneously curtailed as shown in Figure 6.

\subsection{Frequency Adaptive PU-Droops for PVs and BESSs During Larger Under-and Over-Frequency Situations}

Based on the simulations results of Section 3.1. it can be concluded that

- Use of $P U$-blocking is needed from system-wide perspective in order to enable feasible operation of PV 2 (without BESS 3) in Cases $2 \mathrm{a}$ and $2 \mathrm{~b}$ during $50.07 \mathrm{~Hz}$ over-frequency situation.

- With BESS 3 in Case 5b during $49.8 \mathrm{~Hz}$ under-frequency situation however, PV 2 output needs to be curtailed more with $P U$-blocking due to BESS 3 unit's more rapid and extensive participation in system frequency support.

$\bigcirc \quad$ Therefore, use of $P U$-blocking is not recommended from PV curtailment viewpoint when there are both PV and BESS at the same network connection point. On the other hand, simultaneous BESS frequency support with $P U$-blocking logic is higher.

- One potential option to avoid PV 2 curtailment could be disabling Pf-control of BESS 3 during under-frequency events. On the other hand, that is not optimal from whole-system perspective especially if frequency deviation is large and frequency support is needed.

By considering above conclusions there is a need for development of $P U$-droops in order to avoid the mentioned shortcomings and challenges. Therefore, in this section 'frequency adaptive PU-droops' are proposed. The idea, settings, and PSCAD implementation of the frequency adaptive PU-droop are presented in Figure 7. For example with PV 2 and BESS 3 the adaption of frequency adaptive $P U$-droops would mean that when frequency is e.g., $\geq \pm 0.2-0.5 \mathrm{~Hz}$ and between over-voltage limits $1.05-1.15 \mathrm{pu}$ or under-voltage limits $0.85-0.95 \mathrm{pu}$ then active $P U$-droops would be changed from $P U$-droop 1 (Figure 2) to $P U$-droop 2 or 3 (Figure 7).

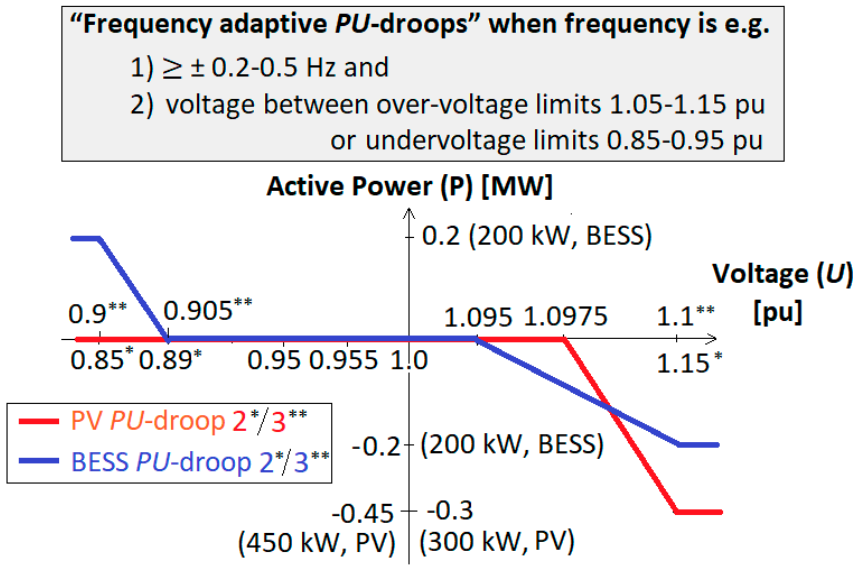

a)

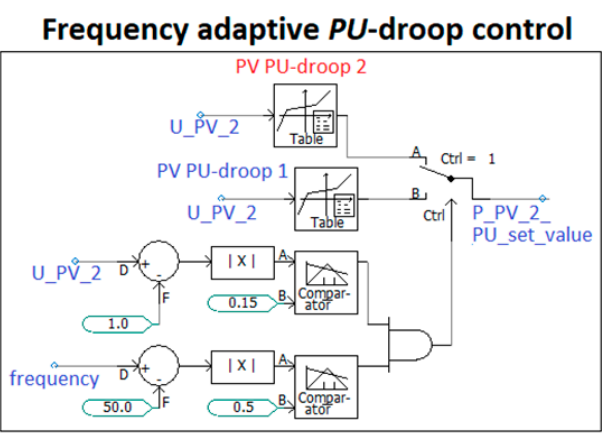

b)

Figure 7. 'Frequency adaptive $P U$-droops' (a) idea and settings for PVs and BESSs during larger under and over-frequency situations and (b) PSCAD implementation of the PV and BESS droops 2.

Standard EN 50160 [45] defines that LV network supply voltage variations under normal operation should not exceed $\pm 10 \%$ of nominal voltage $U_{\mathrm{n}}$ (99\% of the 10 -min mean RMS value over one week) and none of the 10 -min mean RMS values shall exceed $\pm 15 \%$ of $U_{n}$. When comparing these frequency 
adaptive PU-droop settings (Figure 7) to standard EN 50160 [45] requirements regarding supply voltage variation in $\mathrm{LV}$ network, it can be stated that standard requirements are respected.

Frequency adaptive $P U$-droops should be used without $P U$-blocking in cases with PV $+B E S S$ at the same connection point in order to enable PV or BESS unit participation in frequency control markets as well as to maximize smaller LV network connected demand (loads) participation in frequency control.

In Tables 7 and 8, active and reactive power of PV 2 and BESS 3 (Figure 1) as well as PV 2/BESS 3 connection point voltage (U_PV_2, Figure 1) values during larger under-frequencies $(49.4 \mathrm{~Hz})$ in Cases $7 \mathrm{a}$ and $7 \mathrm{~b}$ are presented.

Table 7. PV 2 active $\left(P_{\mathrm{PV} \_2}\right)$ and reactive $\left(Q_{\mathrm{PV} \_2}\right)$ power as well as PV 2 connection point voltage $\left(U_{\mathrm{PV} \_}\right)$during larger under-frequencies $(49.4 \mathrm{~Hz})$ (Figures 1 and 2, Tables 2-6).

\begin{tabular}{|c|c|c|c|c|c|}
\hline Case & $\begin{array}{c}\text { PV } \\
\text { Droop }\end{array}$ & Load Level & $\begin{array}{c}P_{\mathrm{PV} \_2_{2}}, Q_{\mathrm{PV}_{2} 2}, U_{\mathrm{PV}_{\_} 2} \\
\text { Steady-State, } t=25 \mathrm{~s} \\
(\mathrm{~kW}, \mathrm{kVAr}, \mathrm{pu})\end{array}$ & $\begin{array}{c}P_{P V \_2}, Q_{P V \_2}, U_{P V \_2} \\
49.4 \mathrm{~Hz}, t=75 \mathrm{~s} \\
(\mathrm{~kW}, \mathrm{kVAr}, \mathrm{pu})\end{array}$ & $\begin{array}{c}P_{\mathrm{PV} \_2}, Q_{\mathrm{PV} \_2}, U_{\mathrm{PV}_{2} 2} \\
\left.49.4 \mathrm{~Hz}, t=95 \mathrm{~s}{ }^{*}\right) \\
(\mathrm{kW}, \mathrm{kVAr}, \mathrm{pu})\end{array}$ \\
\hline $2 b$ & 1 & Low & $316,-150,1.053$ & $319,-150,1.053$ & $285,-150,1.054$ \\
\hline $7 a$ & 2 & Low & $316,-150,1.053$ & $450,-150,1.095$ & $426,-150,1.100$ \\
\hline $7 a$ & 3 & Low & $316,-150,1.053$ & $450,-150,1.095$ & $416,-150,1.098$ \\
\hline $5 a$ & 1 & Low & $450,-150,1.046$ & $395,-150,1.050$ & $362,-150,1.051$ \\
\hline $7 \mathrm{~b}$ & 2 & Low & $450,-150,1.046$ & $400,-150,1.103$ & $376,-150,1.106$ \\
\hline $7 \mathrm{~b}$ & 3 & Low & $450,-150,1.046$ & $448,-150,1.097$ & $406,-150,1.098$ \\
\hline
\end{tabular}

*) Part of the load also at PV_2 connection point participates in demand response and disconnects from the LV network.

Table 8. BESS 3 active $\left(P_{\text {BESS_3 } 3}\right)$ and reactive $\left(Q_{\text {BESS_3 }}\right)$ during larger under-frequencies $(49.4 \mathrm{~Hz})$ (Figures 1 and 2, Tables 2-6).

\begin{tabular}{|c|c|c|c|c|c|}
\hline Case & $\begin{array}{l}\text { BESS } \\
\text { Droop }\end{array}$ & Load Level & $\begin{array}{c}P_{\text {BESS_3, }} Q_{\text {BESS_3 }} \\
\text { Steady-state, } t=25 \mathrm{~s} \\
(\mathrm{~kW}, \mathrm{kVAr})\end{array}$ & $\begin{array}{c}P_{\text {BESS_3 }}, Q_{\text {BESS_3 }} \\
49.4 \mathrm{~Hz}, t=75 \mathrm{~s} \\
\text { (kW, kVAr) }\end{array}$ & $\begin{array}{c}P_{\text {BESS_3, }} Q_{\text {BESS_3 }} \\
49.4 \mathrm{~Hz}, t=95 \mathrm{~s} \\
(\mathrm{~kW}, \mathrm{kVAr})\end{array}$ \\
\hline $5 a$ & 1 & Low & $-93,-67$ & $-25,-67$ & $-25,-67$ \\
\hline $7 \mathrm{~b}$ & 2 & Low & $-93,-67$ & $144,-67$ & $135,-67$ \\
\hline $7 b$ & 3 & Low & $-93,-67$ & $76,-67$ & $76,-67$ \\
\hline
\end{tabular}

In both cases OLTC set value is $20.0 \mathrm{kV}$. Case $7 \mathrm{a}$ is similar to $2 \mathrm{~b}$ and Case $7 \mathrm{~b}$ is same as $5 \mathrm{a}$ (Table 2). The under-frequencies $(49.4 \mathrm{~Hz}$ ) however, are larger (Table 3) and both Cases $7 \mathrm{a}$ and $7 \mathrm{~b}$ are done without PU-blocking in PV 2/BESS 3 due to their 'frequency adaptive PU-droops' (Figure 7).

From Tables 7 and 8 it can be seen that during larger under-frequencies $(49.4 \mathrm{~Hz})$ in Case 7 a with only PVs (no BESSs), the frequency adaptive $P U$-droop enables larger PV 2 output and power system frequency support also during simultaneous demand response at $t=95 \mathrm{~s}$ (see Case $7 \mathrm{a} \Delta P_{\text {TOTAL_75s }}$ and $\Delta P_{\text {TOTAL_95s }}$ values in Table 9 when compared to Case 2b). Respectively, in Case 7b with PVs and BESSs during $49.4 \mathrm{~Hz}$ under-frequency events the combined frequency support of PV 2 and BESS 3 is increased (see Case $7 \mathrm{~b} \Delta P_{\text {TOTAL_75s }}$ and $\Delta P_{\text {TOTAL_95s }}$ values in Table 9 when compared to Case 5a) and their total effect due to 'frequency adaptive $P U$-droops' is much better from the whole system point of view.

Figure 8 shows the active power behavior of PV 2 and BESS as well as voltage behavior at PV 2 connection point during simulated under-frequency $(49.4 \mathrm{~Hz}$ ) events in Cases $5 \mathrm{a}, 7 \mathrm{~b}$ (with different $P U$-droops, Figure 7 and Tables 7 and 8 ). From Figure 8 and Tables 7 and 8 it can be seen that PV 2 active power $P_{\mathrm{PV} \_2}$ is much less curtailed during under-frequency events in Case $7 \mathrm{~b}$ with $P U$-droop 2 than with $P U$-droop 3. In addition, simultaneous change and increase in BESS 3 active power $P_{\text {BESS_3 }}$ is smaller in Case $7 \mathrm{~b}$ with $P U$-droop 3 than with $P U$-droop 2 . These differences in $P_{\mathrm{PV} \_2}$ and $P_{\text {BESS_3 }}$ behavior during under-frequencies are affected by different $P U$-droops as well as the PSCAD implementation logic presented in Figure $7 \mathrm{~b}$. 
Table 9. Provided frequency support by PV 2 and BESS 3 in different cases during simulated under-frequency $(49.4 \mathrm{~Hz})$ events (see also Tables 7 and 8 ).

\begin{tabular}{|c|c|c|c|c|c|c|}
\hline Case & $\begin{array}{c}\Delta P_{\mathrm{PV} \_2} \\
49.4 \mathrm{~Hz} \\
t=75 \mathrm{~s}(\mathrm{~kW})\end{array}$ & $\begin{array}{l}\Delta P P_{\mathrm{PV} \_2} 49.4 \mathrm{~Hz}, \\
t=95 \mathrm{~s}{ }^{*)}(\mathrm{kW})\end{array}$ & $\begin{array}{c}\Delta P_{\text {BESS_3 }} \\
49.4 \mathrm{~Hz} \\
t=75 \mathrm{~s}(\mathrm{~kW})\end{array}$ & $\begin{array}{c}\Delta P_{\text {BESS } 3} \\
49.4 \mathrm{~Hz}, \\
t=95 \mathrm{~s}^{*)}(\mathrm{kW})\end{array}$ & $\begin{array}{c}\Delta P_{\text {TOTAL_75s }} \\
* *) 49.4 \mathrm{~Hz} \\
t=75 \mathrm{~s}(\mathrm{~kW})\end{array}$ & $\begin{array}{c}\Delta P_{\text {TOTAL_95s }}^{* * *)} \\
49.4 \mathrm{~Hz} \\
t=95 \mathrm{~s}^{*)}(\mathrm{kW})\end{array}$ \\
\hline $2 \mathrm{~b}$ & +3 & -31 & - & - & +3 & -31 \\
\hline $7 a$ & +134 & +110 & - & - & +134 & +110 \\
\hline $7 a$ & +134 & +100 & - & - & +134 & +100 \\
\hline $5 a$ & -55 & -88 & +68 & +68 & +13 & -20 \\
\hline $7 \mathrm{~b}$ & -50 & -74 & +237 & +228 & +187 & +154 \\
\hline $7 \mathrm{~b}$ & -2 & -44 & +169 & +169 & +167 & +125 \\
\hline
\end{tabular}

*) Part of the load also at PV_2 connection point participates in demand response and disconnects from the LV network, ${ }^{* *)} \Delta P_{\text {TOTAL_75s }}=\Delta \bar{P}_{\mathrm{PV}_{-} 2}+\Delta P_{\text {BESS_3 }}$ at $t=75 \mathrm{~s},{ }^{* * *)} \Delta P_{\text {TOTAL_95s }}==\Delta P_{\text {PV_2 }}+\Delta P_{\text {BESS_3 }}$ at $t=95 \mathrm{~s}$.
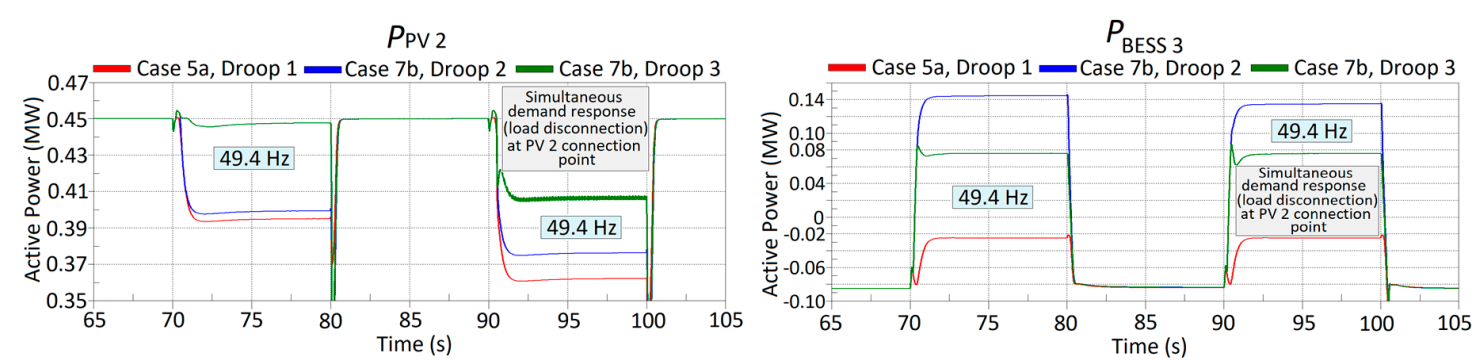

a) UPV2

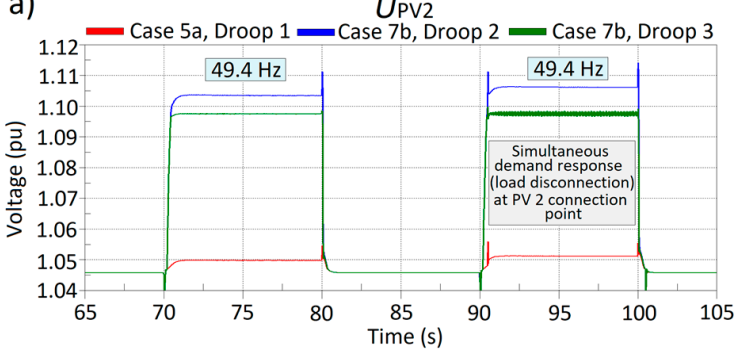

b)

c)

Figure 8. (a) PV 2 active power $P_{\mathrm{PV} \_2}$, (b) BESS 3 active power $P_{\mathrm{BESS} \_3}$, and (c) local voltage $U_{\mathrm{PV} \_2}$ behavior at PV 2 connection point during simulated under-frequency $(49.4 \mathrm{~Hz})$ events in Cases $5 \mathrm{a}$ (PU-droop 1), $7 \mathrm{~b}$ (PU-droop 2), and $7 \mathrm{~b}$ (PU-droop 3), see also Figures 2 and 7.

\section{New Real-Time Adaptive Management Schemes}

In the following, new real-time adaptive management schemes are proposed based on the previous studies and simulation results presented in Section 3.

\subsection{Real-Time Frequency Adaptive PU-Droop}

In Section 3.2. the idea of frequency adaptive PU-droops for PVs and BESSs was presented. The implementation could be smoother without exact frequency $(\geq \pm 0.2-0.5 \mathrm{~Hz})$ and voltage limits for the activation of the frequency adaptive functionality. Therefore, in Figure 9 new 'real-time frequency adaptive PU-droop' for PV and BESS units is proposed when frequency deviation is between $\pm 1.0 \mathrm{~Hz}$ from the nominal frequency $f_{\mathrm{n}}$. If frequency deviation is larger, then similar settings will be used as if the deviation would be $1.0 \mathrm{~Hz}$ from $f_{\mathrm{n}}$. This approach enables constant and smoother frequency adaptive response from the DER units which is also more dependent on the real-time magnitude of frequency change. It should be noted from Figure 9 that different equations will be used for calculation of the $P U$-droop set-points $X_{1}, X_{2}, X_{3}$, and $X_{4}$ depending on the situation (i.e., under- or over-frequency, $f<f_{\mathrm{n}}$ or $f>f_{\mathrm{n}}$ ). In these Figure 9 equations for $\mathrm{X}_{1}, \mathrm{X}_{2}, \mathrm{X}_{3}$, and $\mathrm{X}_{4}$ :

$f=$ measured frequency $(\mathrm{Hz})$

$f_{\mathrm{n}}=$ nominal frequency $(\mathrm{Hz})$ 
$U_{\text {min_ini }}=$ chosen initial minimum voltage set-point value when $f=f_{\mathrm{n}}(\mathrm{pu})$

$U_{\text {max_ini }}=$ chosen initial maximum voltage set-point value when $f=f_{\mathrm{n}}(\mathrm{pu})$

$P_{\mathrm{n}}=$ nominal active power $(\mathrm{MW})$.

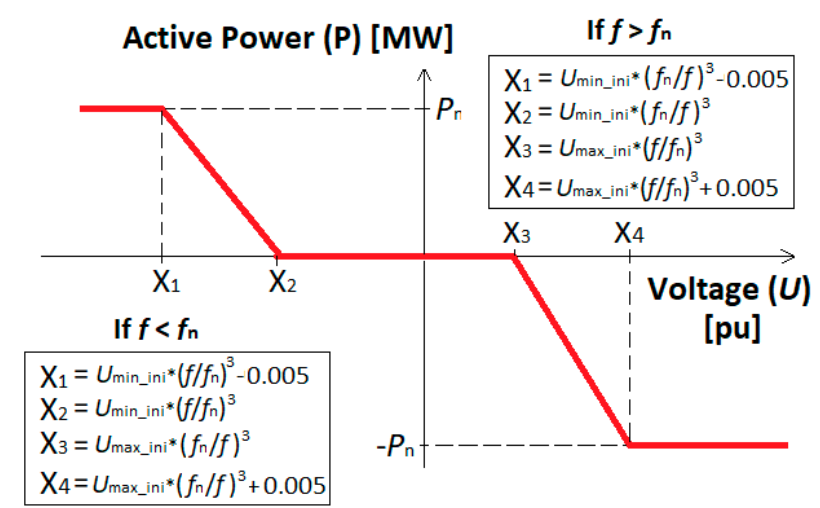

Figure 9. Real-time smooth frequency adaptive $P U$-droop without specific frequency and voltage limits for activation e.g., for BESS unit.

Figure 10 shows example about calculated real-time frequency adaptive $P U$-droop values $X_{1}, X_{2}$, $\mathrm{X}_{3}$, and $\mathrm{X}_{4}$ (Figure 9) for $200 \mathrm{~kW}$ BESS with different frequency values when $f_{\mathrm{n}}=50 \mathrm{~Hz}, P_{\mathrm{n}}=0.2 \mathrm{MW}$, $U_{\text {min_ini }}=0.955 \mathrm{pu}$, and $U_{\text {max_ini }}=1.045 \mathrm{pu}$.

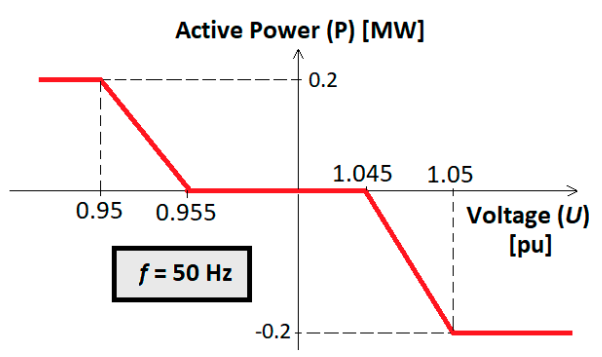

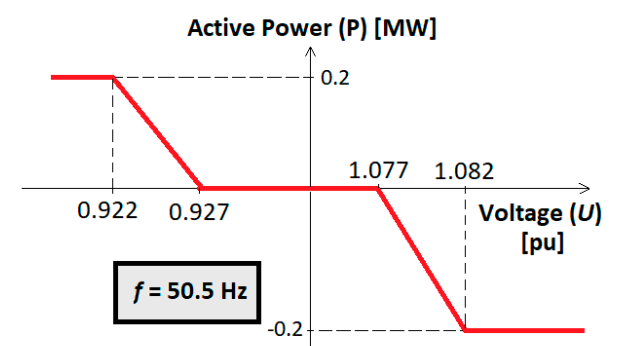

b)

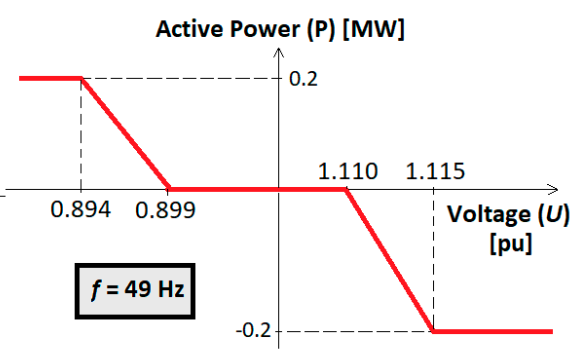

c)

Figure 10. Example of real-time frequency adaptive $P U$-droop values for $200 \mathrm{~kW}$ BESS with (a) $f=$ $50 \mathrm{~Hz},(\mathbf{b}) f=50.5 \mathrm{~Hz}$, and $(\mathbf{c}) f=49 \mathrm{~Hz}\left(f_{\mathrm{n}}=50 \mathrm{~Hz}, P_{\mathrm{n}}=0.2 \mathrm{MW}, U_{\min \_ \text {ini }}=0.955 \mathrm{pu}\right.$, and $U_{\text {max_ini }}=$ $1.045 \mathrm{pu}$, Figure 9).

\subsection{Real-Time HV/MV Substation PQ-Flow Dependent OLTC Setting Value}

Instead of seasonal OLTC settings the OLTC setting value could be based on locally measured real-time active and reactive power flow levels (5 min average $P_{\mathrm{HV}}$ and $Q_{\mathrm{HV}}$ values) between $\mathrm{HV}$ and MV networks at the HV/MV substation as shown in Figure 11. The example in Figure 11 is based on SSG RPW-limits [39]. This proposed new $P Q$-flow dependent OLTC setting value calculation could enable increased DER and PV hosting capacity in distribution networks, less reactive power produced 
by cables (see Equation (1), Section 2.2), and therefore decreased need for voltage control support in MV and LV networks by the flexible energy resources. In addition, simultaneously the availability of, for example, demand response, for provision of system-wide frequency support could be increased.

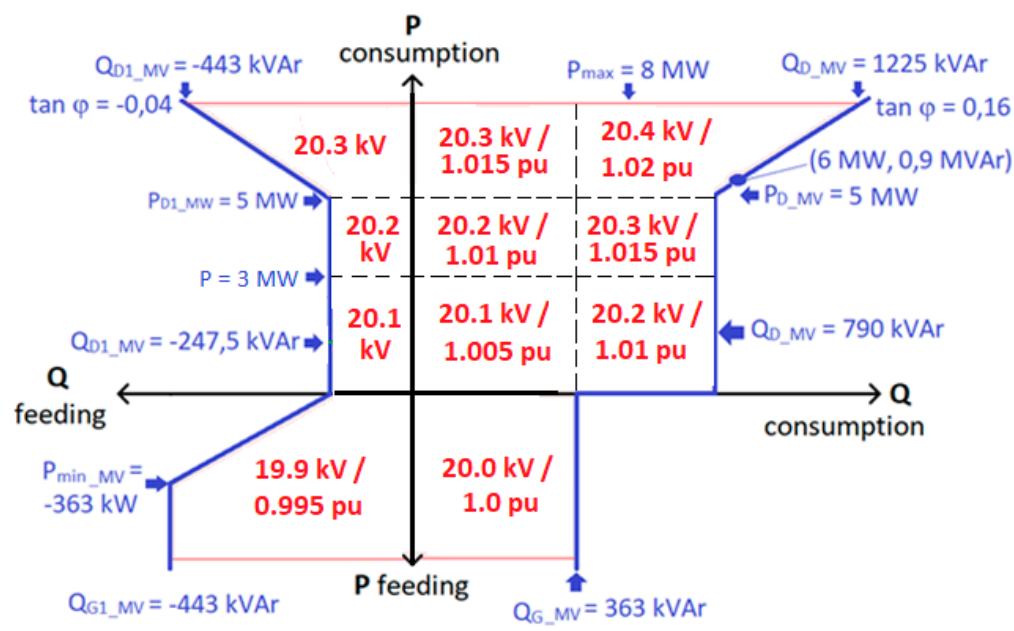

Figure 11. Real-time HV/MV substation $P Q$-flow dependent OLTC setting value with SSG (RPW)-limits.

The proposed $P Q$-flow dependent OLTC setting value (Figure 11) is based on local measurements only and does not require knowledge about minimum and maximum voltages in the corresponding distribution network. Therefore, this approach could be further improved in the future with the real-time measurements based data in order to achieve even more optimized and coordinated determination of OLTC set value and compatible settings for the adaptive $Q U$-droops of the DER units (Section 4.3).

\subsection{Real-Time Adaptive QU-Droop Based on OLTC Setting Value}

If seasonal OLTC settings are utilized, then also QU-droop settings of DER units should be adapted accordingly when OLTC seasonal setting value is changed. This could be done, for example, based on date if also OLTC set value is changed based on the same schedule. This approach was also used as a hypothesis in the simulations presented in Section 3. If the real-time OLTC setting value (e.g., as defined in Section 4.2) however, can be communicated to the DER unit then it could be used as an input to adapt the DER unit QU-droop settings as shown in Figure 12. Regarding the $Q U$-droop settings (Figure 12), the dead-zone size could be modified based on chosen constant $B$ value (from 0.02 to $0.06 \mathrm{pu}$ ) depending on the location of the DER unit in MV or LV network. In addition, if participation of the DER unit to compensate fast voltage variations is emphasized then a smaller constant A value in Figure 12 (e.g., $0.005 \mathrm{pu}$ ) could be used instead of a larger one (e.g., $0.015 \mathrm{pu}$ ) in $Q U$-droop settings.

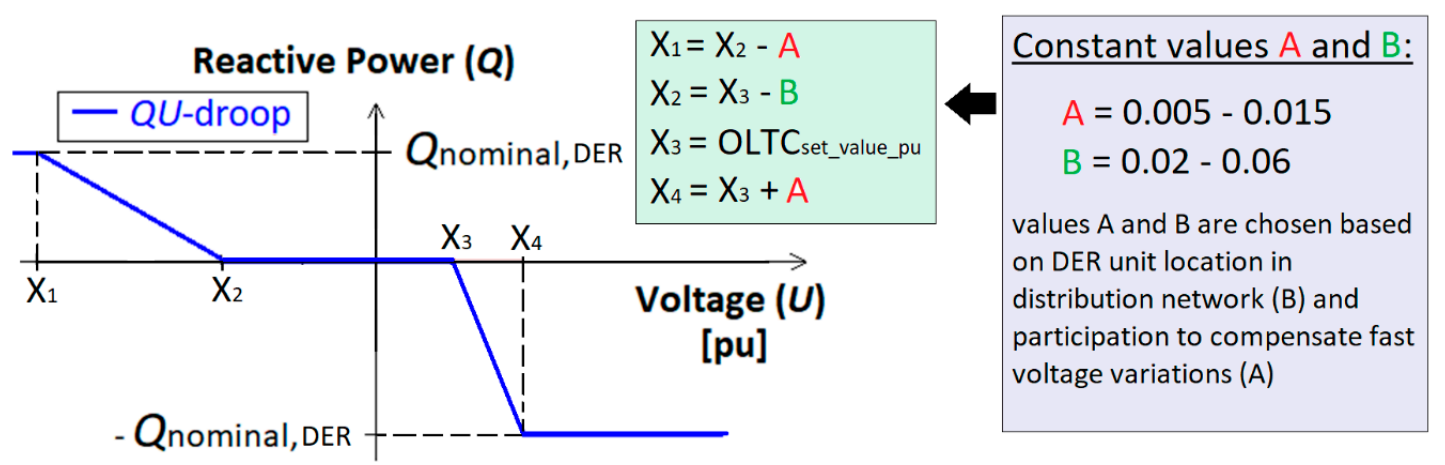

Figure 12. Real-time adaptive DER unit $Q U$-droop based on OLTC set value and constants A and B. 


\section{Conclusions}

In this paper solutions for increasing PV hosting capacity and distribution network connected flexible energy resources improved utilization for local (DSO) and system-wide (TSO) services were studied by PSCAD simulations during very low load situations. The focus was on the potential momentary mutual effects and simultaneous interaction between different functions. Based on the simulation results, it can be concluded that

- $\quad$ PV hosting capacity in LV network can be increased with lower OLTC setting value.

- Feasible and coordinated $Q U-, P U$-, and Pf-droop settings (with dead-zones) of PVs and BESSs are essential in maximizing the provision of their flexibility services.

- During an over-frequency event without BESS, the best frequency support can be achieved by using PU-control blocking logic on PVs.

- PV hosting capacity can be increased to some extent by remote LV voltage measurement from PV connection point to MV/LV substation connected BESS.

- With BESS at the PV connection point however, the PV hosting capacity during steady-state operation can be maximized by simultaneously charging BESS in order to avoid local over-voltages.

- During larger frequency deviations frequency adaptive PU-droops can enable larger PV and BESS power system frequency support as well as maximize smaller LV network connected demand (loads) participation in frequency control.

- Actual implementation logic (e.g., $P U$-blocking or change of active PU-droop with frequency adaptive $P U$-droops) affects the PV and BESS frequency support contribution and the extent of PV curtailment (Table 10).

Table 10. Summary about effect of functionalities implementation logic during simulated very low load situations.

\begin{tabular}{|c|c|c|c|}
\hline DER Unit(s) & Without $P U$-Blocking & With PU-Blocking & $\begin{array}{l}\text { Frequency Adaptive } P U \text {-Droops } \\
\text { (Without } P U \text {-Blocking) }\end{array}$ \\
\hline PV (only) & $\begin{array}{l}\text { Over-frequency support } \\
\text { can be limited }\end{array}$ & $\begin{array}{l}\text { Better over-frequency } \\
\text { support }\end{array}$ & $\begin{array}{c}\text { No difference depending on the } \\
P U \text {-droop settings and over-voltage } \\
\text { limits in the logic (during } \\
\text { under-frequencies) }\end{array}$ \\
\hline $\begin{array}{c}\text { PV + BESS } \\
\text { (at the same } \\
\text { connection point) }\end{array}$ & $\begin{array}{l}\text { During under-frequency } \\
\text { events small PV } \\
\text { curtailment + smaller } \\
\text { BESS contribution }\end{array}$ & $\begin{array}{c}\text { During } \\
\text { under-frequencies PV } \\
\text { curtailment larger }+ \\
\text { BESS contribution larger }\end{array}$ & $\begin{array}{l}\text { Smaller PV curtailment }+ \text { smaller } \\
\text { BESS contribution with lower } \\
\text { over-voltage limit on the } P U \text {-droop } \\
\text { and implementation logic } \\
\text { (during under-frequencies) }\end{array}$ \\
\hline
\end{tabular}

In general, it can be stated that the dead-zones in BESS and PV unit $Q U-, P U-$-, and $P f$-droops are required in order to enable multi-use of active $(P)$ and/or reactive $(Q)$ power for different purposes. In the future, new adaptive management schemes to enable maximum availability of all types and sizes of flexibilities for different local and system level services are needed. New management and DER control methods must be also compatible with other flexibility service options and platforms like flexibility markets. Therefore, in the near future flexible $Q U-, P U-$-, and $P f$-droop functions for DER units are required. Flexible droop functions could also enable local operation optimization at DSO level by updating droop functions setting values and activation limits in a seasonal/monthly/weekly/daily/hourly manner. The adaptation of these droops to the changing network situations, however, should be increasingly done in the future based on the available local and/or remote measurements information. Therefore, in Section 4 new real-time adaptive management schemes for DER units' $P U$-droops, HV/MV substation transformer's OLTC setting value (dependent on the $P Q$-flow through the transformer), and DER units' QU-droops (dependent on OLTC setting value) were also proposed.

It was shown by simulations that with BESS at the PV connection point the PV hosting capacity during steady-state operation and very low load situation can be maximized by simultaneously 
charging BESS. In reality this is only possible if State-of-Charge (SOC) of the BESS is at a suitable level. BESS's SOC naturally has an effect on its capabilities to be used for different control purposes and the ability to provide different flexibility services. In real-life, the SOC-dependency of the BESS PU-droops would be feasible to be implemented as part of the control system in order to be able to maximize benefits to the owner of the assets/flexibility resources. Real-time SOC-level defines the actual BESS ability to provide the different flexibility services. These issues will be considered in the future research.

Author Contributions: Conceptualization, methodology, investigation, H.L.; writing—original draft preparation, H.L., C.P., H.H., M.S.-k., H.K.; writing—review and editing, C.P., H.H., M.S.-k., H.K., N.H. All authors have read and agreed to the published version of the manuscript.

Funding: This work was done as part of FLEXIMAR-project (Novel marketplace for energy flexibility) which is funded by Business Finland and Finnish companies (https://www.univaasa.fi/en/research/projects/fleximar/).

Conflicts of Interest: The authors declare no conflict of interest.

\section{Nomenclature}

\begin{tabular}{|c|c|}
\hline $\mathrm{AC}$ & Alternating Current \\
\hline ANM & Active Network Management \\
\hline BESS & Battery Energy Storage System \\
\hline $\mathrm{CB}$ & Circuit Breaker \\
\hline DC & Direct Current \\
\hline DG & Distributed Generation \\
\hline DER & Distributed Energy Resources \\
\hline DSO & Distribution System Operator \\
\hline ENTSO-E & European Network of Transmission System Operators for Electricity \\
\hline ES & Energy Storage \\
\hline EU & European Union \\
\hline EV & Electric Vehicle \\
\hline HV & High Voltage \\
\hline J06, J07, J08 & MV feeders in the study case \\
\hline $\mathrm{LV}$ & Low Voltage \\
\hline MV & Medium Voltage \\
\hline NC & Network Code \\
\hline OLTC & On-Load Tap Changer \\
\hline PSCAD & Power System Simulation Software \\
\hline P-controller & Proportional controller \\
\hline PI-controller & Proportional-Integral controller \\
\hline PV & Photovoltaic \\
\hline RES & Renewable Energy Sources \\
\hline RfG & Requirements for Generators \\
\hline RMS & Root Mean Square \\
\hline RPW & Reactive Power Window \\
\hline SOC & State-of-Charge \\
\hline SSG & Sundom Smart Grid \\
\hline TSO & Transmission System Operator \\
\hline WT & Wind Turbine \\
\hline$\omega$ & Angular frequency \\
\hline $\mathrm{C}$ & Capacitance \\
\hline $\cos \varphi$ & Power factor \\
\hline $\cos \varphi(\mathrm{P})$ & Active Power dependent power factor \\
\hline $\mathrm{f}$ & Frequency \\
\hline$f_{n}$ & Nominal frequency $(\mathrm{Hz})$ \\
\hline
\end{tabular}




\begin{tabular}{|c|c|}
\hline I & Current \\
\hline$I_{\text {meas }}$ & Measured Current \\
\hline $\mathrm{I}_{\mathrm{d}}$ & Current direct $(\mathrm{d})$ component \\
\hline$I_{d \_r e f}$ & Current direct $(\mathrm{d})$ component reference value \\
\hline $\mathrm{I}_{\mathrm{q}}$ & Current quadrature $(\mathrm{q})$ component \\
\hline $\mathrm{I}_{\mathrm{q} \_ \text {ref }}$ & Current quadrature (q) component reference value \\
\hline $\mathrm{L}$ & Inductance \\
\hline $\mathrm{P}$ & Active Power \\
\hline P_MV_flow & Active Power flow between HV and MV networks \\
\hline Pf or $P(f)$ & Active Power-Frequency \\
\hline PU or $\mathrm{P}(\mathrm{U})$ & Active Power-Voltage \\
\hline$\Delta \mathrm{P}_{\text {BESS_3 }}$ & Active Power change of BESS unit 3 \\
\hline$\Delta \mathrm{P}_{\mathrm{PV} \_2}$ & Active Power change of PV unit 2 \\
\hline$\Delta \mathrm{P}_{\text {TOTAL_75s }}$ & Total Active Power change during simulation at $t=75 \mathrm{~s}$ \\
\hline$\Delta \mathrm{P}_{\text {TOTAL_95s }}$ & Total Active Power change during simulation at $t=95 \mathrm{~s}$ \\
\hline$P_{\text {BESS_1 }}$ & Active Power of BESS unit 1 \\
\hline$P_{\text {BESS_3 }}$ & Active Power of BESS unit 3 \\
\hline$P_{n}$ & Nominal active power \\
\hline$P_{P V}$ & Active Power of PV unit \\
\hline P PV_2 & Active Power of PV unit 2 \\
\hline$P_{W T}$ & Active Power of Wind Turbine (WT) \\
\hline P_ref & Active Power reference value \\
\hline PQ & Active Power-Reactive Power \\
\hline Q & Reactive Power \\
\hline Q_MV_flow & Reactive Power flow between HV and MV networks \\
\hline$Q_{\text {cable }}$ & Total Reactive Power of a cable \\
\hline$Q_{\text {consumption }}$ & Reactive Power consumed by a cable \\
\hline $\mathrm{Q}_{\text {production }}$ & Reactive Power produced by a cable \\
\hline$Q_{\text {unb }}$ & Reactive Power unbalance \\
\hline $\mathrm{Q}(\mathrm{P})$ & Reactive Power-Active Power \\
\hline QU or Q(U) & Reactive Power-Voltage \\
\hline QBESS_1 & Reactive Power of BESS unit 1 \\
\hline $\mathrm{Q}_{\mathrm{BESS} \_3}$ & Reactive Power of BESS unit 3 \\
\hline $\mathrm{Q}_{\mathrm{PV} \_2}$ & Reactive Power of PV unit 2 \\
\hline Q_ref & Reactive Power reference value \\
\hline $\mathrm{t}$ & Time \\
\hline $\mathrm{U}$ & Voltage \\
\hline $\mathrm{U}_{\mathrm{n}}$ & Nominal Voltage \\
\hline $\mathrm{U}_{\text {min_ini }}$ & Chosen initial minimum voltage set-point value \\
\hline $\mathrm{U}_{\max \_ \text {ini }}$ & Chosen initial maximum voltage set-point value \\
\hline $\mathrm{U}_{\mathrm{PV} \_2}$ & Connection point voltage of PV unit 2 \\
\hline $\mathrm{V}_{\mathrm{d}}$ & Voltage direct $(\mathrm{d})$ component \\
\hline $\mathrm{V}_{\mathrm{q}}$ & Voltage quadrature $(q)$ component \\
\hline $\mathrm{V}_{\mathrm{PCC}}$ & Voltage at the point of common coupling \\
\hline V_ref & Voltage reference value \\
\hline
\end{tabular}

\section{References}

1. Mohandes, B.; El Moursi, M.S.; Hatziargyriou, N.; El Khatib, S. A review of power system flexibility with high penetration of renewables. IEEE Trans. Power Syst. 2019, 34, 3140-3155. [CrossRef]

2. Laaksonen, H.; Hovila, P. FlexZone concept to enable resilient distribution grids-possibilities in sundom smart grid. In Proceedings of the CIRED Workshop 2016, Helsinki, Finland, 14-15 June 2016.

3. Astapov, V.; Divshali, P.H.; Söder, L. The potential of distribution grid as an alternative source for reactive power control in transmission grid. In Proceedings of the 20th European Conference on Power Electronics and Applications-EPE 2018, Riga, Latvia, 17-21 September 2018. 
4. Hafezi, H.; Laaksonen, H. Autonomous soft open point control for active distribution network voltage level management. In Proceedings of the 13th IEEE PowerTech 2019, Milan, Italy, 23-27 June 2019.

5. Hes, S.; Kula, J.; Svec, J. Technical solutions for increasing der hosting capacity in distribution grids in the Czech Republic in terms of European project INTERFLEX. In Proceedings of the 25th International Conference on Electricity Distribution-CIRED 2019, Madrid, Spain, 3-6 June 2019.

6. Ulasenka, A.; Del Rio Etayo, L.; Cirujano, P.; Ortiz, A.; Brandl, R.; Montoya, J. Holistic coordination of smart technologies for efficient lv operation, increasing hosting capacity and reducing grid losses. In Proceedings of the 25th International Conference on Electricity Distribution-CIRED 2019, Madrid, Spain, 3-6 June 2019.

7. Wang, Y.; Xu, Y.; Tang, Y.; Syed, M.H.; Guillo-Sansano, E.; Burt, G.M. Decentralized-Distributed Hybrid Voltage Regulation of Power Distribution Networks Based on Power Inverters. IET Gener. Transm. Distrib. 2019, 13, 444-451. [CrossRef]

8. Divshali, P.H.; Söder, L. Improving hosting capacity of rooftop PVS by quadratic control of an LV-Central BSS. IEEE Trans. Smart Grid 2017, 10, 919-927. [CrossRef]

9. Parthasarathy, C.; Hafezi, H.; Laaksonen, H.; Kauhaniemi, K. Modelling and simulation of hybrid PV \& BES systems as flexible resources in Smartgrids-Sundom smart grid case. In Proceedings of the 13th IEEE PowerTech 2019, Milan, Italy, 23-27 June 2019.

10. Divshali, P.H.; Alimardani, A.; Hosseinian, S.H.; Abedi, M. Decentralized cooperative control strategy of microsources for stabilizing autonomous VSC-Based Microgrids. IEEE Trans. Power Syst. 2012, 27, 1949-1959. [CrossRef]

11. Worthmann, K.; Kellett, C.M.; Braun, P.; Grüne, L.; Weller, S.R. Distributed and decentralized control of residential energy systems incorporating battery storage. IEEE Trans. Smart Grid 2015, 6, 1914-1923. [CrossRef]

12. Nieto, A.; Efstratiadi, M.-A.; Currie, A.; Coughlan, K.; Do, S. Coordinated operation of a grid scale energy storage system with tap changer for voltage control on primary substations. In Proceedings of the 25th International Conference on Electricity Distribution-CIRED 2019, Madrid, Spain, 3-6 June 2019.

13. Weckx, S.; D'Hulst, R.; Driesen, J. Primary and secondary frequency support by a multi-agent demand control system. IEEE Trans. Power Syst. 2015, 30, 1394-1404. [CrossRef]

14. Mokhtari, G.; Ghosh, A.; Nourbakhsh, G.; Ledwich, G. Smart robust resource control in LV network to deal with voltage rise issue. IEEE Trans. Sustain. Energy 2013, 4, 1043-1050. [CrossRef]

15. Lee, S.-J.; Kim, J.-H.; Kim, C.-H.; Kim, S.-K.; Kim, E.-S.; Kim, D.-U.; Mehmood, K.K.; Khan, S.U. Coordinated control algorithm for distributed battery energy storage systems for mitigating voltage and frequency deviations. IEEE Trans. Smart Grid 2016, 7, 1713-1722. [CrossRef]

16. Miao, L.; Wen, J.; Xie, H.; Yue, C.; Lee, W.-J. Coordinated control strategy of wind turbine generator and energy storage equipment for frequency support. IEEE Trans. Ind. Appl. 2013, 51, 2732-2742. [CrossRef]

17. Alam, M.J.E.; Muttaqi, K.M.; Sutanto, D. Mitigation of rooftop solar pv impacts and evening peak support by managing available capacity of distributed energy storage systems. IEEE Trans. Power Syst. 2013, 28, 3874-3884. [CrossRef]

18. Nazariet, M.H.; Costello, Z.; Feizollahi, M.J.; Grijalva, S.; Egerstedt, M. Distributed frequency control of prosumer-based electric energy systems. IEEE Trans. Power Syst. 2014, 29, 2934-2942.

19. Moghadam, M.R.V.; Ma, R.T.B.; Zhang, R. Distributed frequency control in smart grids via randomized demand response. IEEE Trans. Smart Grid 2014, 5, 2798-2809. [CrossRef]

20. Xing, L.; Mishra, Y.; Tian, Y.; Ledwich, G.; Su, H.; Peng, C.; Fei, M. Dual consensus based distributed frequency control for multiple energy storage systems. IEEE Trans. Smart Grid 2019, 10, 6396-6403. [CrossRef]

21. Yu, L.; Chu, C. Consensus-based secondary frequency and voltage droop control of virtual synchronous generators for Isolated AC Microgrids. IEEE J. Emerg. Sel. Top. Circuits Syst. 2015, 5, 443-455.

22. Baros, S.; Llic, M.D. A Consensus approach to real-time distributed control of energy storage systems in wind farms. IEEE Trans. Smart Grid 2019, 10, 613-625. [CrossRef]

23. Nguyen, D.H.; Khazaei, J. Multi-agent time-delayed fast consensus design for distributed battery energy storage systems. IEEE Trans. Sustain. Energy 2018, 9, 1397-1406. [CrossRef]

24. Pilloni, A.; Pisano, A.; Usai, E. Robust finite time frequency and voltage restoration of inverter-based microgrids via sliding mode cooperative control. IEEE Trans. Ind. Electron. 2018, 65, 907-917. [CrossRef]

25. Hu, J.; Lanzon, A. Distributed finite time consensus control for heterogeneous battery energy storage systems in droop-controlled microgrids. IEEE Trans. Smart Grid 2019, 10, 4751-4761. [CrossRef] 
26. Sugihara, H.; Yokoyama, K.; Saeki, O.; Tsuji, K.; Funaki, T. Economic and efficient voltage management using customer-owned energy storage systems in a distribution network with high penetration of photovoltaic systems. IEEE Trans. Power Syst. 2013, 28, 102-111. [CrossRef]

27. Giannitrapani, A.; Paoletti, S.; Vicino, A.; Zarrilli, D. Optimal allocation of energy storage systems for voltage control in LV distribution networks. IEEE Trans. Smart Grid 2017, 8, 2859-2870. [CrossRef]

28. Zarrilli, D.; Giannitrapani, A.; Paoletti, S.; Vicino, A. Energy storage operation for voltage control in distribution networks: A receding horizon approach. IEEE Trans. Control Syst. Technol. 2018, 26, 599-609. [CrossRef]

29. Sami, S.S.; Cheng, M.; Wu, J.; Jenkins, N. A Virtual energy storage system for voltage control of distribution networks. CSEE J. Power Energy Syst. 2018, 4, 146-154. [CrossRef]

30. Wang, L.; Liang, D.H.; Crossland, A.F.; Taylor, P.C.; Jones, D.; Wade, N.S. Coordination of multiple energy storage units in a low-voltage distribution network. IEEE Trans. Smart Grid 2015, 6, 2906-2918. [CrossRef]

31. Wang, Y.; Tan, K.T.; Peng, X.Y.; So, P.L. Coordinated control of distributed energy-storage systems for voltage regulation in distribution networks. IEEE Trans. Power Deliv. 2016, 31, 1132-1141. [CrossRef]

32. Jayasekara, N.; Masoum, M.A.; Wolfs, P.J. Optimal operation of distributed energy storage systems to improve distribution network load and generation hosting capability. IEEE Trans. Sustain. Energy 2016, 7, 250-261. [CrossRef]

33. Rigas, A.; Messinis, G.; Hatziargyriou, N. Application of topology identification on optimal bess sizing in distribution systems. In Proceedings of the 8th IEEE PES Innovative Smart Grid Technologies Conference Europe-ISGT Europe 2018, Sarajevo, Bosnia and Herzegovina, 21-25 October 2018.

34. Jahromi, A.A.; Majzoobi, A.; Khodaei, A.; Bahramirad, S.; Zhang, L.; Paaso, A.; Lelic, M.; Flinn, D. Battery Energy storage requirements for mitigating PV output fluctuations. In Proceedings of the 8th IEEE PES Innovative Smart Grid Technologies Conference Europe-ISGT Europe 2018, Sarajevo, Bosnia and Herzegovina, 21-25 October 2018.

35. Zhang, Y.; Ren, S.; Dong, Z.Y.; Xu, Y.; Meng, K.; Zheng, Y. Optimal placement of battery energy storage in distribution networks considering conservation voltage reduction and stochastic load composition. IET Gener. Transm. Distrib. 2017, 11, 3862-3870. [CrossRef]

36. Yue, M.; Wang, X. Grid Inertial response-based probabilistic determination of Energy Storage System Capacity under high solar penetration. IEEE Trans. Sustain. Energy 2015, 6, 1039-1049. [CrossRef]

37. Wang, Y.; Xu, Y.; Tang, Y.; Liao, K.; Syed, M.H.; Guillo-Sansano, E.; Burt, G. Aggregated energy storage for power system frequency control: A finite-time consensus approach. IEEE Trans. Smart Grid 2019, 10, 3675-3686. [CrossRef]

38. Vasilj, J.; Gros, S.; Jakus, D.; Sarajcev, P. Multi-market scheduling of battery storages within renewable portfolios. In Proceedings of the 8th IEEE PES Innovative Smart Grid Technologies Conference Europe-ISGT Europe 2018, Sarajevo, Bosnia and Herzegovina, 21-25 October 2018.

39. Laaksonen, H.; Sirviö, K.; Aflecht, S.; Hovila, P. Multi-objective active network management scheme studied in sundom smart grid with MV and LV network connected DER units. In Proceedings of the 25th International Conference on Electricity Distribution-CIRED 2019, Madrid, Spain, 3-6 June 2019.

40. Laaksonen, H.; Hovila, P.; Kauhaniemi, K.; Sirviö, K. Advanced islanding detection in grid interactive microgrids. In Proceedings of the CIRED 2018 Workshop, Ljubljana, Slovenia, 7-8 June 2018.

41. Laaksonen, H.; Hovila, P.; Kauhaniemi, K. Combined islanding detection scheme utilizing active network management for future resilient distribution networks. In Proceedings of the IET 14th International Conference on Developments in Power System Protection-DPSP 2018, Belfast, UK, 12-15 March 2018.

42. Laaksonen, H. Reliable islanding detection with active MV network management. In Proceedings of the CIRED 2014 Workshop, Rome, Italy, 11-12 June 2014.

43. EU Commission. Commission Regulation (EU) 2016/631 of 14 April 2016 Establishing A Network Code on Requirements for Grid Connection of Generators. Available online: https://eur-lex.europa.eu/legal-content/ EN/TXT/?uri=OJ:JOL_2016_112_R_0001\#d1e8030-1-1 (accessed on 12 May 2020).

44. Faranda, R.S.; Hafezi, H.; Leva, S.; Mussetta, M.; Ogliari, E. The optimum PV plant for a given solar DC/AC converter. Energies 2015, 8, 4853-4870. [CrossRef]

45. Standard EN 50160. Voltage Characteristics of Electricity Supplied by Public Electricity Networks; European Committee for Electrotechnical Standardization (CENELEC): Brussels, Belgium, 2010.

(C) 2020 by the authors. Licensee MDPI, Basel, Switzerland. This article is an open access article distributed under the terms and conditions of the Creative Commons Attribution (CC BY) license (http://creativecommons.org/licenses/by/4.0/). 